Portland State University

PDXScholar

6-8-1979

\title{
A Cost Analysis and Recidivism Study of a Pre-trial Diversion Program
}

Ruth E. Green

Portland State University

Follow this and additional works at: https://pdxscholar.library.pdx.edu/open_access_etds

Part of the Criminology Commons, and the Social Work Commons Let us know how access to this document benefits you.

Recommended Citation

Green, Ruth E., "A Cost Analysis and Recidivism Study of a Pre-trial Diversion Program" (1979).

Dissertations and Theses. Paper 2772.

https://doi.org/10.15760/etd.2768

This Thesis is brought to you for free and open access. It has been accepted for inclusion in Dissertations and Theses by an authorized administrator of PDXScholar. Please contact us if we can make this document more accessible: pdxscholar@pdx.edu. 


\section{A COST ANALYSIS AND RECIDIVISM STUDY \\ OF A PRE-TRIAL DIVERSION PROGRAM}

by

RUTH E. GREEN

A practicum submitted in partial fulfillment of the requirements for the degree of

MASTER OF SOCIAL WORK

Portland State University

1979 
TO THE OFFICE OF GRADUATE STUDIES AND RESEARCH:

The advisor approves the practicum of Rutih E. Green presented June 8, 1979.

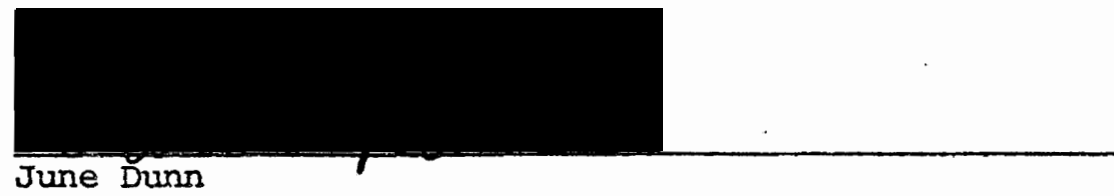

And

The Director of Health and Welfare Planning Council, in association with Cascade Research Center, has supported the development of this study as initial findings of a program evaluation under contract with clark County, washington.

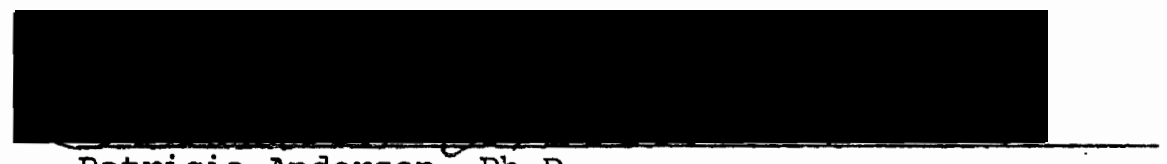

Patricia Anderson, Ph.D.

And

Michael Malone, M.A. 
The Director of Health and Welfare Planning Council, in association with Cascade Research Center, approves the publishing of this material.

Patricia Anderson, Ph.D. 
TABLE OF CONTENTS

PAGE

I. INTRODUCTION . . . . . . . . . . . . . . . . i

II. REVIEW OF THE IITERATURE

Introduction .. . . . . . . . . . . . . . 1

Historical Development . . . . . . . . . . 3

Pre-Trial Diversion ...... . . . . . . . . 5

Manpower-Based Pre-Trial Diversion Programs . . . . . 7

Inclusive Evaluation Studies of Pre-Trial Diversion . . 12

Summary . . . . . . . . . . . . . . . . 14

III. DESCRIPTION OF THE CLARK COUNTY PROSECUTING ATTORNEY'S

PRE-TRIAI DIVERSION PROGRAM, VANCOUVER, WASHINGTON . • •

IV. RESEARCH DESIGN

Method . . . . . . . . . . . . . . 19

Procedure . . . . . . . . . . . . . . . 21

V. RESULTS

Social and Demographic Description . . . . . . . 23

Program Success Rates and Recidivism Rates . . . . 26

Comparison Recidivism Rates . . . . . . . . . 28

Cost Efficiency Results . . . . . . . . . . . 29

Pre-Habilitation Activity . . . . . . . . . . 32 
PAGE

VI. CONCLUSIONS AND RECOMMENDATIONS • . . . . . . . . . • • 34

VII. SOURCES CONSULTED . . . . . . . . . . . . . . . . 37

APPENDICES :

APPENDIX A: Admission Criteria . . . . . . . . . . 40

APPENDIX B: Computer Worksheet . . . . . . . . . . . 41

\section{LIST OF TABLES :}

TABLE 1: Diversion Programs and Recidivism Rates . . . . 15-16

TABLE 2: Age Grouping . . . . . . . . . . . . . . 23

TABLE 3: Success Rate By Age Grouping . . . . . . . . . . 24

TABLE 4: Personal Income . . . . . . . . . . . . . . 25

TABLE 5: Success Rate By Employment . . . . . . . . . . 25

TABLE 6: Post-Program Crime By Number of Rearrest . . . • • 27

TABLE 7: Comparison Recidivism Rates . . . . . . . . . 29

TABLE 8: Cost Difference Between Diversion and Adjudication • 29

TABLE 9: 1976 Cost Analysis, Clark County . . . . . . . . 30

TABLE 10: 1976-1978 cost Analysis . . . . . . . . . . 31 
This research project is a report of cost findings and rearrest rates from a program evaluation of a pre-trial diversion program. In 1978 Cascade Research Center (CRC) contracted with Clark County, washington, to determine the cost-effectiveness and cost-efficiency of the Pre-Habilitation agency, which implements the Prosecuting Attorney's Pre-Trial Diversion Program.

Begun in December of 1973 by James E. Carty, County Prosecutor, the program provides an alternative for first-time felony offenders without an extensive record of crime in order to rebuild a stable life pattern that is acceptable to the community. As an incentive, the prosecutor drops criminal charges and expunges the record upon successful completion of the year-long program.

The objectives of the program are to stop the criminal pattern of behavior before it becomes implanted in the individual by interrupting destructive labeling processes yet providing retribution to society and restitution to the victim. Basic conditions of the program include job stability, established residence, and regular contact with the agency.

The author was introduced to the agency in the Fall of 1978 as a data collector and primarily assisted in the questionnaire design, data collection, and the computer programming.

Once retrieved, the data from 205 case files were readied for keypunching, computer operations, and cohort data comparison. This report was taken from the first computer runs for analysis of costs and recidivism rates. 
Besides an analysis of costs to operate the program versus prosecuting an offender through the criminal justice system and an account of recidivism rates, the $\mathrm{CRC}$ contracted for a formative program evaluation. Their objectives began with an exploration of the following hypotheses :

1. Among offenders there are two major categories which can be distinguished in terms of consistency of anti-social behavior. Law breakers are offenders who commit a crime in response to an isolated and temporary situation and do not have an established history of anti-social behavior. Criminals are those offenders for which the current offense is but another crime in an ongoing series of anti-social behavior.

2. A non-stigmatizing approach for dealing with lawbreakers will be more effective in terms of preventing subsequent crime than the traditional punitive approach currently used for dealing with criminals.

3. A non-traditional approach to criminal justice processing will be more efficient in terms of costs to the community than the traditional punitive approach currently used for dealing with criminals.

4. The diversion of lawbreakers will serve to reduce potential congestion in the Clark County Criminal Justice system by reducing the caseloads of detectives, probation and parole officers, prosecutors, public defenders and courts.

5. The cost associated with diverting a lawbreaker will be less than the costs associated with the traditional adjudication process required for the same individual.

and provide the following information:

1. Each of the hypotheses 1isted in the introduction ... will be examined by comparing Diversion clients with the cohort samples selected for the evaluation. This comparison will focus on recidivism and cost for adjudication.

2. A successful/unsuccessful client typology will be developed which will describe those characteristics most common among successful Diversion clients. The information generated in this effort could be used in the development of a screening scale for prosepctive Diversion clients.

3. Extensive breakdowns of the cost incurred in the diversion of clients will be examined to produce a cost per client, cost per contact, cost per successful client, and cost per staff position profile of agency operation. These cost breakdowns will ... determine whether the project is maintaining its cost effectiveness. 
4. A review of the internal data collection system will be provided which details alternative approaches for maintaining client information ... to refine ... record keeping systems ...

5. A study of the impact of the new policies implemented in september of 1978 will be included to determine the impact of giving the responsibility for becoming a diversion client to the offender himself, the requirement that the offender confess to his crime before becoming eligible for diversion, and the increase in treatment tenure.

6. A functional perspective will be included in the final report which addresses the relationship between the Diversion project and other elements of the Clark County Criminal Justice System. This functional assessment will ... determine areas where program redundancy can be minimized.

Complete results of the CRC program evaluation will contribute to national as well as local evaluation needs because pre-trial diversion, in its short existence, has not been well scrutinized for its efficiency or effectiveness. Besides program evaluation, the final report promises a rich resource of demographic data. Demographic descriptions enable the comparison of several studies to determine if they have similar populations, assists in matching subjects, and provides a basis for identifying factors contributing to success and failure independent of the program intervention.

The ensuing initial report describes the literature of diversion, the research design, initial results, and conclusions and recommendations. 
REVIEW OF THE IITERATURE

\section{Introduction}

History reveals bodily mutilation, expatriation, and, in more recent times, imprisonment as societal choices of punishment for those who broke common law. Progressively, man added the dimension of antisocial behavior change to social control. Unfortunately, the prison environment has not been an effective means of changing behavior. In addition, most offenders do not require lengthy confinement to protect themselves or society. A need has risen for a bridge between freedom and prison.

Community-based corrections programs, as an alternative to confinement, are one response to this need. They are correctional activities that occur at any point in the corrections process and take place within the community. At the beginning of an offender's experience with the criminal justice system, he has not been labeled as an offender. A police officer may decide to give a summons instead of making an arrest. A judicial officer may choose to release him on his own recognizance or on bail. At this point, he may or may not receive further correctional attention. If so, some newer examples of programs he may enter are community service employment, informal probation, or court diversion. If convicted and committed to the control of the corrections agency; he may receive one of other forms of community-based services such as youth services, expanded use of probation, volunteer and paraprofessional services, regional correctional center attention, community custody, and foster care or 
substitute homes. Court diversion projects, the topic of this cost analysis and recidivism rate study, is an example of a humane, restorative, and cost-efficient alternative before the conviction process. The literature proceeds in this fashion: historical development of diversion, pre-trial diversion objectives, evaluative studies of counseling and guidance diversion programs, inclusive reports of diversion efforts, and summary. Each program study follows a format of describing program characteristics, cost factors, program success rates, and recidivism rates. Issues such as the decision-making process and quality of such evaluative research is discussed elsewhere. 
Historical Development

Diverting criminals away from the traditional justice system is a product of a new movement, an "alternatives movement," created by this phenomena -- recognition that society contributes to criminal behavior and erosion of effectiveness in our current justice system (Perlstein and Phelps, 1975): The American tradition has focused on the individual as a free agent, able to discern between right and wrong. Thus, it was assumed that, to commit a crime, a person must either willfully disregard legitimate authority or suffer from a shortcoming of character or mental illness. However, recent years have taught that crime is a symptom of failure and disorganization of the community because the community deprives offenders of the opportunity to develop lawabiding conduct (Perlstein and Phelps, 1975). An example is that minorities are isolated as a group from the conventional environment of jobs and roles that most people enjoy.

Besides the realization that society contributes to criminal behavior, the systems of justice are ineffective. That is, they are fragmented nonsystems marked by unequal quality of justice; inadequate fiscal, manpower, and training resources; shortages in equipment and facilities; and lack of relevant research and evaluation to provide some measure of effectiveness (Aaronson et al., 1977). These and other problems were punctuated in the 1967 President's Crime Commission Report (Aaronson et al., 1977). As an illustration of inadequacies in prison facilities, a report from Washington describes overcrowding and overcontrol problems to be a result of increased felony convictions and a reduction in the use of probation as a sentencing alternative 
(Błumberg, 1978).

Within the justice system itself came the realization that a move was necessary to insure better disposition of cases. Congressional appropriation of funds followed and diversion processes were created at various points in the system. The first processing point is pretrial, which is release of the individual to an alternative instead of being jailed while awaiting disposition of his case. An example is permitting the release of persons on their own recognizance. Another is the Alternate Routes program instituted in Orange County, California, in 1969. Instead of being routed through the juvenile justice system, juveniles were provided counseling and guidance after being referred by police, schools, parents, or neighbors for crime committed (Gilbert, 1977). The second process point is post-trial, where, once found guilty, the individual who is a first offender or who commits a non-serious crime may, for example, pay a fine instead of going to jail. The third process point is post-incarceration, which is an increase in the use of parole or other community-based alternatives to shorten this period. An example of the latter is a half-way house for those about to be released to society from prison (Perlstein and Phelps, 1975).

The creation of diversion processes by the justice system is an example of adjudicatory interests in the alternatives movement. Adjudicatory alternatives seek effective means for determining guilt or innocence and for imposing judgments on the accused. Further, by sacrificing formality of traditional procedures and disposing of certain offenders quickly and at the earliest possible stage, effi- 
ciency is promoted (Aaronson et al., 1977).

With the advent of labeling theory in the field of sociology, another system, the corrections system, also became attracted to diversion processes. Correctional alternatives are concerned with the correctional disposition of offenders after adjudication. This includes the substance of the criminal sanction (securing conformity to law) and the application of retribution, rehabilitation, and deterrence (Aaronson et al., 1977). Richard Lundman shows how consequent diversion programs borrowed from labeling theory (Iundman, 1976). Applied to corrections, labeling theory states that an individual who commits an act of deviance, is caught, and then publicly labeled as deviant, changes his sense of self because of the public's awareness and critical application of the label. The change is a result of internalization of a deviant image of self. Therefore, since labeling starts the process of building a pattern of deviant behavior, corrections took the stance that the less an offender becomes enmeshed in the criminal process and the criminal label, the easier it will be for him later to be retrieved for a life of lawfulness (Roesch, 1978).

\section{Pre-Trial Diversion}

of all pre-trial release alternatives, deferred or formal diversion is the focus of this cost analysis and recidivism research. A review of the literature is helpful for defining this concept, tracing its development, and evaluating success in terms of costs and recidivism rates. 
Born in 1965 in Gennessee County, Michigan, the concept of diversion was begun by The Honorable F. Leonard. As prosecuting attorney for that county, he started the first formalized deferred prosecution program known as the Gennessee County Citizens Probation Authority (Beha et al., 1976). However, the Vera Institute of Justice, with its Manhattan Court Employment Project in 1967 and Project Crossroads, operated by the National Committee for Children and Youth in Washington, D.C., were two successful demonstration programs which fueled the spread of pre-trial intervention/diversion programs across the country. As of January 1978, there were nearly 50 diversion programs for both juvenile and adult offenders (Blumberg, 1978).

While adult and juvenile programs differ in criteria for eligibility and program components, for both the aim of diversion is to provide an alternative to the traditional court processing of offenders. Most programs select defendants shortly after arrest and accept first offenders who have committed nonviolent crimes. During the period of diversion, prosecution is postponed. As an incentive for successful completion of the pre-trial program conditions, charges are dismissed and, most signifiant of all, no conviction record is filed.

Two functions of diversion exist in relation to adjudicatory and correctional perspectives. In fact, "diversion" and "intervention" are frequently used interchangeably. From the adjudicatory vantage, diversion has the primary function of case screening, based on the traditional discretionary authority of the prosecutor or the court. "The objective is to conserve official criminal justice resources for those requiring close control and supervision, removing from the sanction of the court defendants who may not require a full criminal 
disposition" (Galaway, 1977). From the correctional perspective, diversion is frequently spoken of as "intervention." The primaxy function now becomes rehabilitation, that is, "to identify defendants in need of treatment and to deliver the requisite services with the expectation of providing a more effective alternative to normal criminal or juvenile justice system processing" (Lundman, 1976). Frequently, both functions operate in diversion programs.

Manpower-Based Pre-Trial Diversion Programs: An Overview

An ambitious effort to produce a range of benefits from pre-trial reform is exemplified by the 1967 Manhattan and Crossroads Projects, both manpower-based programs. Sponsored by the Department of Labor, they were designed to provide counseling, job placement, and access to job training and educational opportunities to juvenilesand young adults who had committed misdemeanors. The range of benefits are described below :

\footnotetext{
"Alleviation of congested court calendars and flexibility in case processing were foreseen as relatively immediate benefits by the introduction of a pre-trial diversion program into the District of Columbia court system. Longer-range benefits anticipated, in addition to the reduction of costs incurred in the prosecution, detention, trial, and incarceration of individuals 'processed' in the usual manner, included altering the image of the courts in the eyes of the accused and the community... The participant, for his part, was provided an alternative to a permanently recorded label of 'delinquent' or 'criminal,' as well as an avenue through which to gain a foothold in the legitimate opportunity structure of society. Society and the community, of course, would benefit from more and better equipped men and women in its labor force as well as from a decrease in the number of potential recidivists." (Harris and Moitra, 1978)
} 
When Project Crossroads was evaluated, this three-month program produced a recidivism rate for adult participants over a year't time at 9 percent and the control group, 22 percent (Mullen, 1977). Program costs came to about $\$ 500$ per person (Noble, 1977).

Methodologies used by these programs invite critics. The Manhattan program is reported as having had a failure rate and recidivism rate of under 5 percent; therefore, "the remaining participants look better than a group which still contains its failures" (Mullen, 1977). Other conclusions criticized the validity of the control group, a non-random, retrospective group of non-participating defendants; comparison of only successful program participants with the comparison group; and pre-post program comparison of participant status as a criterion for screening selection (Mullen, 1977).

Operation de Novo, sponsored in 1971 by the Department of Labor, provided employment and support services and was similar in criteria eligibility to the Manhattan and Crossroads Projects above but added felonies after six months (Mullen, 1977).

Costs for the six-month program ran about $\$ 700$ per client. While no assessment of de Novo's impact on caseload or total expenditure of local probation departments was made in 1974, Nimmer claims that this figure is similar to the costs for other employment programs and is less than the average cost of probation counseling in Minneapolis (Nimmer, 1974). 
costs were $\$ 700$ per participant compared to $\$ 875$ for traditionally channeled individuals.

The Juvenile Services Program (JSP) for Pinellas County, Florida, provided services to 12-16 year-olds in vocational counseling, training and job placement, academic education on a tutorial and small-group basis, and personal and social counseling (Quay and Love, 1977).

Because two groups were formally referred to the program and one group was not, it is necessary to review the recidivism rates compared to control groups in two statements. An average of 39 percent of the two groups were rearrested 13 months after completing the program while the informally referred group's average was 24 percent. Controls for each averaged 51 percent and 64 percent, respectively (Quay and Love, 1977). Recidivism of all three groups' successful participants was an averaged 28 percent, and, of failures, 44 percent (Quay and Love, 1977). These figures were not broken down into the formally and informally referred groups for either the program participants or the control group.

Following the national trend to expand provision of human services, in 1969 the Orange County, California Board of Supervisors moved to consider effective alternatives to temper increased social problems in the county. By 1971 a pilot project, Community services project (CSP), grew out of their planning activity, and Alternate Routes (AR) was one of several efforts. Staffed by trained counselors, AR was a diversion program for youthful offenders and a supplement to the traditional 
juvenile justice system. Goals included less costly treatment, satisfying treatment to both the youths and their families, usefulness to key community institutions, and reduced recidivism among participants (Gilbert, 1977).

A summative evaluation was performed, including criteria as follows: attainment of short-term performance objectives, adjudged diversion (this means what each referral by institution would have been if the project had not existed), satisfaction of users (client survey), timeliness of treatment, relative cost of treatment, recidivism, and impact on the juvenile justice system indicators (Gilbert, 1977). For the purposes of this research study, relative cost of treatment and recidivism will be reported.

Each youth was tracked through AR and a control group, through the traditional system, but in only 23 percent of the cases could evaluators get data for the latter network. However, partial data revealed a higher cost for controls than for AR (Gilbert, 1977).

Recidivism rates were computed between $A R$ and a control group in six-month and one-year periods. After six months, 29 percent of AR youth were rearrested while 71 percent were not, compared to 53 and 47 percent of traditionally processed youth, respectively. After one year, the failure figures increased to 34 percent for AR youth and 65 percent for the others (Roesch, 1978). Although not truly experimental in design, this study gave the first successful report for diversion efforts, especially in terms of recidivism data. 
Although literature is incomplete in its description, the Adult Diversion Program in Champaign County, Illinois was begun in 1975 . Criteria were that the voluntary participant reside in the county up to a year, have no felony convictions, and have no more than two recent misdemeanors. The opportunity to receive counseling and other needed services was the major component of the program treatment (Roesch, 1978). A distinguishing mark of this program is its adherence to "true" diversion, whereby an individual is not simply transferred from one part of the justice system to another. "Cases accepted into the program will not be returned for prosecution in the event of failure to comply with a program agreement or in the event of a subsequent arrest" (Gottheil, 1979). It is this voluntary aspect which characterizes "true" diversion.

Evaluation of this program was not requested by its funding commission; therefore, cost data and rates of recidivism are not available.

\section{Inclusive Evaluation Studies of Pre-Trial Diversion}

Ronald Roesch discusses two reviews of diversion programs. Roberta Rovner-Pieczenik concluded that several of the fifteen projects increased employment and reduced recidivism. However, the validity of those reports was questioned because only one used a control group to assess recidivism rates (this was the Dade County Project above) (Roesch, 1978). Furthermore, five of the 15 projects used an inadequate method of selecting a comparison group; the group was selected from defendants traditionally processed before the start of diversion projects. Motivation and cooperation factors as well as changes in 
economic and employment conditions were unaccounted for. The remaining projects used a pre- and post-test design only on their own diversion participants; consequently, no generalizations to diversion effectiveness were possible (Roesch, 1978).

The second major review of diversion projects agreed that evaluations so far have been inadequate. Joan Mullen and others analyzed the same 15 projects above as well as other programs, concluding that the "evaluations performed have been based on fairly crude quasiexperimental designs" (Roesch, 1978).

Marvin Bohnstedt joins Ronald Roesch in comprehensive evaluating, but he restricted his study to the most common types of diversion in California: police diversion as an alternative to probation referrals and probation diversion as an alternative to court processing. He researched 11 California projects specifically for cost factors and recidivism data (Bohnstedt, 1978). By estimating what the cost of processing diversion participants in the traditional system would have been, he found that the overall costs were higher for the diversion participants. There were no net savings because of the group of clients who otherwise would have been referred to probation intake and processed no further. The national average cost of probation and intake is $\$ 100$; beyond probation intake, it is $\$ 500$. Their savings were one-fourth the cost of those who would have been processed beyond probation intake (Bohnstedt, 1978).

Recidivism results of Bohnstedt's study of 11 programs were positive. Within six months of referral to the project, 5 percent of the participants had lower rearrest rates than the comparisons. Broken 
down into separate programs, results are diffused because some programs accepted high risk clients while others did not (Bohnstedt, 1978).

In addition to the above two studies, Robert Fishman reviewed records of nearly 3,000 men in 18 different programs sponsored by the Criminal Justice Coordinating Council in New York City. He revealed a 41 percent recidivism rate, which is very high. However, the results are of limited value because there was no control group (Roesch, 1978).

\section{Summary}

Most of the journal articles described and reported results of individual pre-trial diversion programs. Major characteristics included a target group of juveniles or young adults, some link to probation functions, and an emphasis on gaining employment. Fewer program descriptions admitted adults and focused on counseling. Covering a broad spectrum of program emphases, the inclusive evaluation studies enhanced the review by adding composite information about diversion action since its beginnings nearly 15 years ago.

To summarize the evaluative comments, one may conclude that inadequate testing for recidivism rates prevails and little valid evaluation data exists on pre-trial diversion. Major criticisms are poor or no selection of comparison or control groups and poor design to acquire recidivism data.

Following is a table summarizing the research findings from the literature described above. 


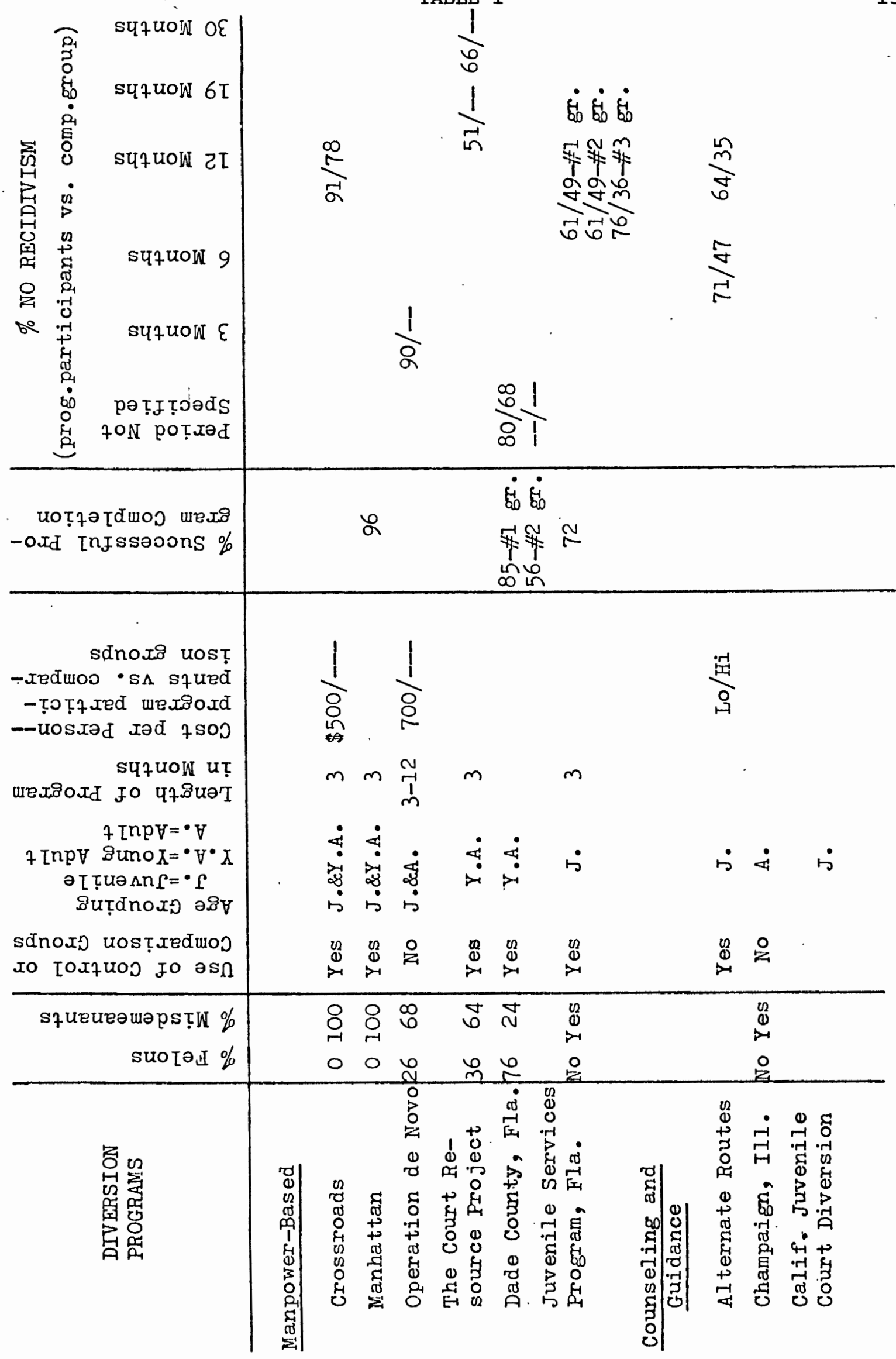




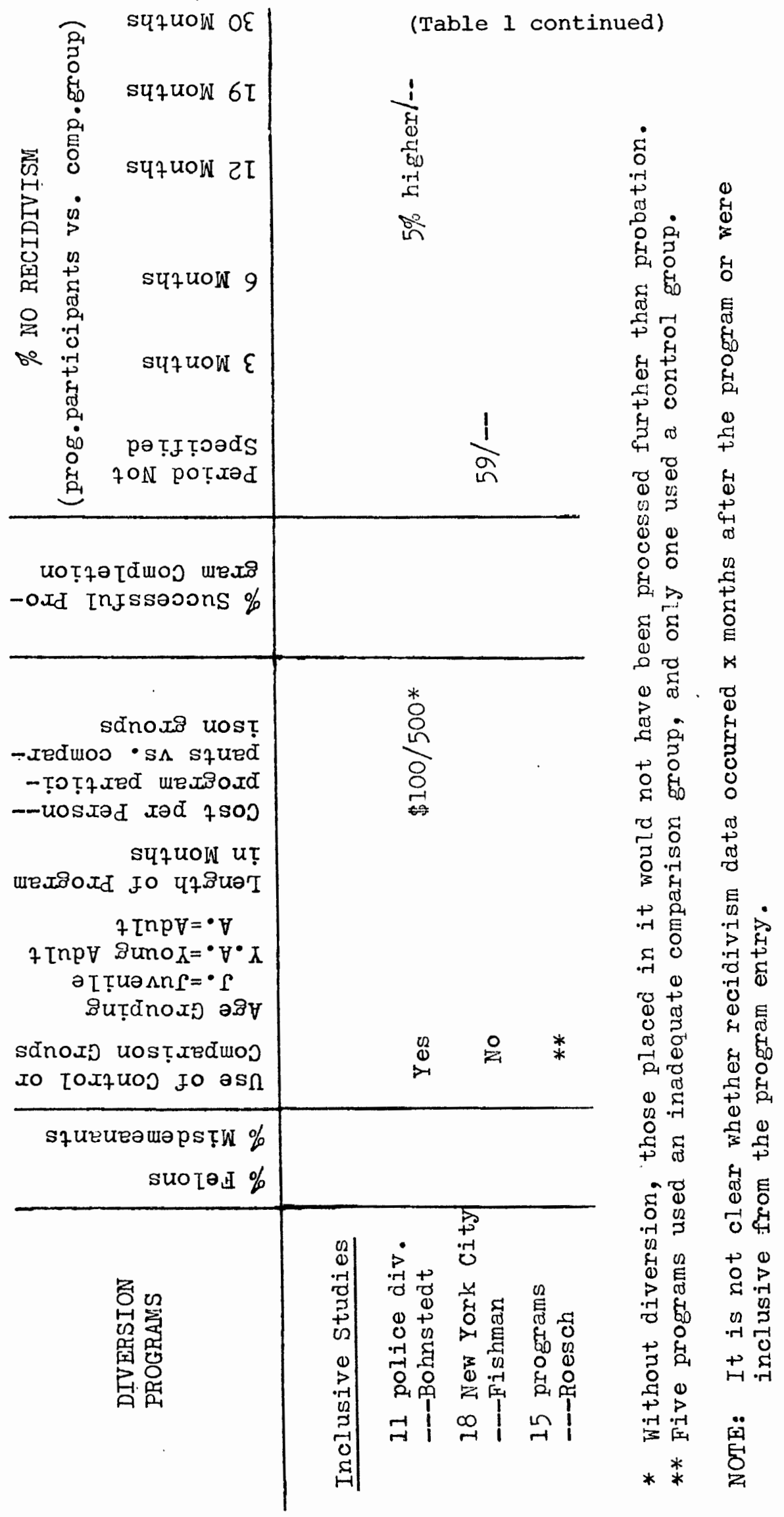




\section{DESCRIPTION OF THE CLARK COUNTY \\ PROSECUTING ATTORNEY'S PRE-TRIAL DIVERSION PROGRAM, VANCOUVER, WASHINGTON}

The Clark County Diversion Program began in December, 1973 with the purpose of helping offenders avoid the stigma of a criminal record and assisting in their change of lifestyle to one within standards generally acceptable to the community.

An hypothesis for the program is that this arrangement is more humane to and prevents subsequent crime by the offender which has not established a pattern of anti-social behavior. Expectations of the program are that costs for diverting offenders will be less than traditional adjudication and that caseloads in the criminal justice system of the county will be reduced. This study investigates only the cost factors and hypothesis of recidivism.

The program serves adults without previous felony records and who have not committed violent crime. Admission criteria include the prevailing mood of the community, the potential damage done to community standards in each instance, the attitude of the offender, and several additional seconđary factors. (See Appendix A)

The procedure for alternative adjudication requires the following steps. If the Chief Criminal Deputy or his designee passes the offender on the criteria, a counselor from the Pre-Habilitation agency interviews him. Once accepted, the offender and counselor design a program to fit the particular requirements for rehabilitation. The prosecutor reviews the plan and, upon approval, proceeds to arrange for a contract. At this point, the offender consults an attorney, reviews the prepared 
program, and if acceptable, enters into a contract with the prosecutor. This contract defines the accused offense (s), contains a waiver to $a$ ' speedy trial and admission of guilt, refers to the program letter; states the 12-month length of obligation, guarantees confidentiality of communications with his counselor, and promises no criminal charge will be filed if the contract is successfully fulfilled. The offender also agrees to reimburse the county for a portion of the cost of his program or to perform the equivalent in community service hours. Signatures of the prosecutor and offender on the agreement and attached affidavit seal the contract.

A description of the Pre-Habilitation agency provides an understanding of its activities. The director, three counselors including CETA workers when available, a half-time secretary, and occasional volunteers or student interns make up the personnel. Each counselor utilizes social service agencies and community resources to fulfill contract conditions. Examples are employment services, alcohol and drug treatment programs, and mental health counseling. 
RESEARCH DESIGN

The cost analysis and recidivism design below include the method, which describes the selection of diversion subjects and the comparison group, questionnaire development, and computer operations, and the procedure.

Method

Selection of Diversion Sample. A systematic sample of every second case from December, 1973 through December, 1977 totalled 205 cases. Each case had been successfully completed or unsuccessfully terminated. Selection of Comparison Group. A cost-efficiency study ideally requires an experimental design using data from a comparable community on criminals who would have been eligible from the same time period for a pre-trial diversion program but who had been processed through that community's regular channels of prosecution. A search of oregon counties for a cohort group was unsuacessful, revealing that 17 counties, including those most accessible, already operated diversion programs of varying emphasis and design. At the same time, it was discovered that two neighboring counties in washington nearly matched programs to clark County. Instead of a cohort group, data was used for comparison of recidivism rates with the two similar diversion programs. For purposes of this research study, only figures from Snohomish County will be compared.

Questionnaire Development. A questionnaire was developed to collect demographic, correctional, and cost data. Thirty percent of the form recorded the number of monthly report forms, telephone calls, and vis- 
its to the office per month. From the application for diversion, it was possible to retrieve demographic and correctional data, which made up one-third of the questions. Program referral activity and contracting conditions were taken from the letter of program acceptance and counselor notes. Recidivism data was added after review of the files.

The questionnaire was designed to correspond to computer needs for programming. The sheets used for data collection consisted of a series of IBM coding sheets. Since the questionnaire was divided into question number and data location, variable list, variable name and value code, number of columns, and format, a simple transfer of file data to the IBM sheet eliminated a time-consuming task of recoding. The questionnaire was used to create a computer worksheet. (See Appen$\operatorname{dix} B)$

Use of the instrument in the first days of data collection revealed room for improvement in questionnaire design. Therefore, revisions and corrections were made, accordingly. Inadvertently, previous criminal history was collected but not in a meaningful context. The author designed a telephone survey questionnaire in order to sample program participants. Cascade Research Center's final evaluation will contain those results in the form of current living patterns, including stability of job and living arrangement, for a written, follow-up description to be compared against client typologies discovered by the research study.

Computer Operations. The Statistical Package for the Social Sciences (SPSS) computer programming system was selected to perform the statistical analyses and develop client typologies through crosstabulations. 
SPSS is a computer program language and system which simplifies the process of data analysis. It avoids the time-consuming tasks of performing statistical procedures by hand or by the use of single-purpose computer programs to create partial information which in turn is recoded for a noncompatible computer program until intended results are produced. SPSSS integrates the routine tasks of data processing around which a series of statistical programs are built to perform statistical analysis. For example, the statistics command card could perform one or all of the following frequency analyses: skewness, range, or minimum and maximum values. Choice of correction tests between variables, called crosstabulations, include chi-square, phi, cramer's V, contingency coefficient, lambda, uncertainty coefficient, tau b, tau c, eta, gamma, somer's D, and zero-order and partial gammas.

\section{$\underline{\text { Procedure }}$}

The procedure was to collect court cost and recidivism data from Clark County; program success rates and individual demographic information from the diversion files at the Pre-Habilitationagency; and obtain comparative recidivism data from Snohomish County. Cost efficiency was measured by comparing diversion program costs to the cost of processing through the traditional channels in the criminal justice system. Client characteristics amenable to success and program components related to success were approachable through the use of crosstabulations. Correlations between successful and unsuccessful participants and recidivism data showed how often and which type of participant committed crime after leaving the program. 
The definition of cost efficient was any positive difference or savings between the two procedures described above.

The time period begins in December, 1973 (or January, 1974) and ends in December, 1978, covering four years of completed diversion cases. The recidivism data, then, accounts for all participants in this time period since starting the program. Consequently, for some, as much as three years' recidivism data appears. 
The results are reported under the following headings: social and demographic description, program success rates and recidivism rates; cost efficiency results; and a separate section on Pre-Habilitation activity.

Social and Demographic Description

The following describes the social, economic, and demographic aspects of participants from 1974 to 1978 of a total sample of 205 cases.

The sex breakdown was 169 male and 36 female.

The age range is grouped below:

TABLE 2

$\begin{array}{lrrrrccccc}\text { Age } & 16-17 & 18-21 & 22-26 & 27-29 & 30-39 & 40-45 & 58 & 73 & \text { Total } \\ \text { Number } & 35 & 83 & 36 & 17 & 19 & 9 & 1 & 1 & 205\end{array}$

The racial composition was 125 white, 2 black, 2 American Indian, 1 Spanish origin, and 2 other. Data was not available for 73 cases. Over half were single, 50 were married, 11 had separated, and 17 were divorced. Marital status was missing for five persons. The number of dependents probably reflects the single status, with 127 persons reporting none. As many as eight dependents were reported by others. 
Using the same age categories, a crosstabulation with success rates of program completion revealed the following:

TABLE 3

Age $\quad 16-17 \quad 18-21 \quad 22-26 \quad 27-29 \quad 30-39 \quad 40-45 \quad 58 \quad 73^{\text {Total }}$

Success-

ful

28

68

33

16

19

9

$\begin{array}{lll}1 & 1 & 175\end{array}$

Unsuc-

cessful

$7 \quad 15$

3

1

0

0

$0 \quad 0 \quad 26$

Missing : 4 4

Tests of significance revealed that the 16-21 age category has higher risk offenders than anyone over $21(\mathrm{P}<.03) .85$ percent of the unsuccessfuls are 21 or younger while 55 percent of the successfuls are older than 21 .

With 7 missing cases, 12 persons completed ninth grade; 24, tenth grade; 42, eleventh grade; and 86 graduated from high school or obtained the equivalent of it. Beyond high school, 13 gained another year of education and 9, two years. Eight persons have had either 15, 16, 17, or 18 years of education.

As for military experience, 43 had been in the armed services and 95 had not. The remainder were unaccounted for.

Annual income was reported exactly as categorized on the client application found in the files. The amount may reflect the spouse's contribution because both personal annual income and other household income were requested. 
TABLE 4

Less Than 3,00031

$3,000-4,000$

$4,000-5,000$

$5,000-6,000$

Missing: 116
$6,000-7,000$

$7,000-8,000 \quad 4$

$8,000-9,000 \quad 3$

$9,000-10,000 \quad 4$
$11,000-12,000 \quad 8$

$12,000-13,000 \quad 2$

$13,000-14,0001$

$14,000-15,0004$

Over 15,000

As for their first source of income, employment by another person received the highest frequency of 87 (42.4 percent); other, 18 (8.8 percent); unemployment compensation, 14 (6.8 percent); public assistance, 7 (3.4 percent); GI Bill, 2 ( 1.0 percent); SSI, 1 (.5 percent); and 76 (37.1 percent) cases were missing. For a second source of income, other was 7 (3.4 percent); GI Bill, 4 (2.0 percent); public assistance, 2 (1.0 percent); employment by another person, 2 ( 1.0 percent); SSI, 1 (.5 percent); unemployment compensation, 1 (.5 percent); and 187 (91.2 percent), missing. Data for third sources of income were available for two persons, and they were both designated as other.

A crosstabulation was run on success rate and employment status at program entrance. While 65 (42.2 percent) were successful yet unemployed, 14 (58.3 percent) were unsuccessful yet unemployed. While 89 (51.9 percent) were employed and successful, 10 (41.7 percent) were employed and unsuccessful.

TABLE 5

$\begin{array}{lllll} & \text { Unemployed } & \text { Part-Time } & \text { Full-Time Self } \\ \text { Employment } & \text { No. Percent } & \text { No. Percent } & \text { No. Percent No. Percent }\end{array}$

$\begin{array}{lllllllll}\text { Successful } & 65 & (42.2) & 9 & (5.8) & 71 & (46.1) & 9 & (5.8) \\ \text { Unsuccessful } & 14 & (58.3) & 1 & (4.2) & 9 & (37.5) & 0 & (0.0)\end{array}$


Program Success Rates and Recidivism Rates

A crosstabulation of success rates with type of felony committed before program entrance revealed 63 successful/5 unsuccessful for possession of a controlled substance, 44/12 for second degree burglary, and $22 / 4$ for grand larceny for the most frequent felonies. The remainder were varied and can be classified in this manner: victimless, 1/0; crime against property, 35/8; and crime against people, $11 / 1$.

During treatment, three persons were rearrested but not terminated for those arrests, while six were returned for rearrests. Misdemeanors --victimless crime made up 3 ( 1.5 percent) of those arrests and felonies--crime against property made up 5 (2.4 percent) while 196 (95.6 percent) of participants remained arrest-free. Those arrested twice while in the program committed misdemeanors--victimless crime 3 (1.5 percent); traffic offenses, 1 (.5 percent); and felonies--crime against property, 1 (.5 percent) or probation violation, 1 (.5 percent).

The recidivism data was grouped two ways: (1) arrests for possession of marijuana, a series of misdemeanors, felonies, type unknown, and does not apply and (2) misdemeanor--crime against people, misdemeanor--crime against property, misdemeanor--victimless crime, traffic offense, felony--crime against people, felony--crime against property, felony--victimless crime, probation violation, and parole violation. Results are listed in the table below for the first categorization and second categorization, respectively. 
TABLE 6

GENERALIZED CATEGORIES

Recidivism Rates

\begin{tabular}{|c|c|c|c|c|c|c|c|c|}
\hline & \multicolumn{2}{|c|}{$\begin{array}{c}\text { First } \\
\text { Rearrest }\end{array}$} & \multicolumn{2}{|c|}{$\begin{array}{l}\text { Second } \\
\text { Rearrest }\end{array}$} & \multicolumn{2}{|c|}{$\begin{array}{c}\text { Third } \\
\text { Rearrest }\end{array}$} & \multicolumn{2}{|c|}{$\begin{array}{c}\text { Fourth } \\
\text { Rearrest }\end{array}$} \\
\hline & No. & Percent & No。 & Percent & No. & Percent & No. & Percent \\
\hline Does Not Apply & 15 & $(7.3)$ & 0 & $(0.0)$ & 0 & $(0.0)$ & 0 & $(0.0)$ \\
\hline Marijuana & 2 & $(1.0)$ & 0 & $(0.0)$ & 0 & $(0.0)$ & 0 & $(0.0)$ \\
\hline $\begin{array}{l}\text { Series of Mis- } \\
\text { demeanors }\end{array}$ & 2 & $(1.0)$ & 1 & $(0.5)$ & 0 & $(0.0)$ & 1 & $(0.5)$ \\
\hline Felony & 1 & $(0.5)$ & 1 & $(0.5)$ & 0 & $(0.0)$ & 0 & $(0.0)$ \\
\hline Type Offense & & & & & & & & \\
\hline Not Known & 3 & $(1.5)$ & 0 & $(0.0)$ & 0 & $(0.0)$ & 0 & $(0.0)$ \\
\hline No Rearrest & 180 & $(87.8)$ & 202 & $(98.5)$ & 204 & $(99.5)$ & 202 & $(98.5)$ \\
\hline Missing: & 2 & $(1.0)$ & 1 & $(0.5)$ & 1 & $(0.5)$ & 2 & $(1.0)$ \\
\hline
\end{tabular}

CRIMINAL CATEGORIES

\begin{tabular}{|c|c|c|c|c|c|c|c|c|}
\hline \multicolumn{9}{|l|}{ Felony } \\
\hline$\overline{\text { People }}$ & 0 & $(0.0)$ & 0 & $(0.0)$ & 0 & $(0.0)$ & 0 & $(0.0)$ \\
\hline Property & 0 & $(0.0)$ & 1 & $(0.5)$ & 0 & $(0.0)$ & 0 & $(0.0)$ \\
\hline Victimless & 0 & $(0.0)$ & 0 & $(0.0)$ & 0 & $(0.0)$ & 0 & $(0.0)$ \\
\hline \multicolumn{9}{|l|}{ Probation/ } \\
\hline Parole & 0 & $(0.0)$ & 0 & $(0.0)$ & 0 & $(0.0)$ & 0 & $(0.0)$ \\
\hline \multicolumn{9}{|l|}{ Misdemeanor } \\
\hline People & 0 & $(0.0)$ & 0 & $(0.0)$ & 0 & $(0.0)$ & 0 & $(0.0)$ \\
\hline Property & 1 & $(0.5)$ & 1 & $(0.5)$ & 0 & $(0.0)$ & 0 & $(0.0)$ \\
\hline Victimless & 5 & $(2.4)$ & 2 & $(1.0)$ & 0 & $(0.0)$ & 0 & $(0.0)$ \\
\hline Probation/ & & & & & & & & \\
\hline Parole & 0 & $(0.0)$ & 0 & $(0.0)$ & 0 & $(0.0)$ & 0 & $(0.0)$ \\
\hline Traffic & 5 & $(2.4)$ & 1 & $(0.5)$ & 0 & $(0.0)$ & 0 & $(0.0)$ \\
\hline
\end{tabular}


(Table 6 Continued)

\begin{tabular}{llll} 
First & \multicolumn{1}{c}{ Second } & \multicolumn{1}{c}{ Third } & Fourth \\
Rearrest & Rearrest & Rearrest & Rearrest \\
No. Percent & No. Percent & No. Percent & No. Percent
\end{tabular}

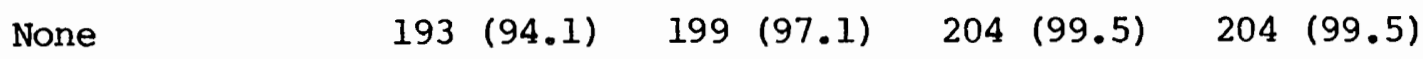

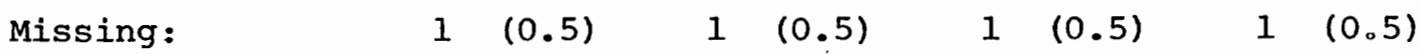

There appears to be a discrepancy in the figures reported for misdemeanors and felonies between the two categories. For the first rearrest, figures of 4.0 percent versus 5.3 percent, excluding missing and does not apply data, are reported by the first and second groupings, and 1.0 percent versus 2.5 percent for the second rearrest. Since the second categorization is defined in criminal justice terms, it will be considered more accurate.

Looking at the second group of recidivism rates, there are no felonies committed for first rearrests, but misdemeanors add up to 5.3 percent. Second rearrests include 1 felony against property, or .5 percent, and a total of 2.0 percent misdemeanors. No clear evidence for third or fourth rearrests were reported while there is consistently .5 percent missing data for each rearrest.

\section{Comparison Recidivism Rates}

Snohomish County reported a recidivism rate during the program of 3 percent for felonious crime and 5 percent for misdemeanant crime for successful participants in their pre-trial diversion program over the two years of their existence. Compared to Snohomish County, Clark County produces 2.5 percent less felonious crime and 2.3 percent more misdemeanant crime. Again, 2.0 percent of data is missing. 
TABLE 7

$\begin{array}{cl}\text { Misdemeanor } & \text { Felony } \\ \text { Percent } & \text { Percent }\end{array}$

Snohomish County Diversion

Total over two years;

$\begin{array}{lll}\text { successful participants; } & 5.0 & 3.0\end{array}$

during the program

Clark County Diversion

Total over four years;

all participants;

7.3

0.5

during and after program

Cost Efficiency Results

From a 1976 comparison study by the Prosecuting Attorney's office, the following criminal cost data was obtained. The time period covered December 1973 to september 1976, and the comparison is with the alternative adjudication process should a felony plea of guilty and subsequent probation for one year have occurred.

TABLE 8

Cost per person for plea and one year of probation

Cost per person for diversion

for one year

At that time, they had 280 total cases which was multiplied by the savings per person and totalled a savings of $\$ 482,400$.

In more detail, the cost breakdown was as follows: 
TABLE 9

1976 Cost Analysis - Clark County *

Traditional Adjudication Process

Public Defender

$\begin{array}{ll}\text { per person re: felony plea } & \$ 150.00\end{array}$

State Probation and Parole

per felony probation per year at $\$ 1.50$ per day 550.00 .

Prosecution and court

per person re: felony plea

(two-day jury trial $=\$ 8443.00$ )

1580.00

Plea and subsequent probation for one year

$\$ 2280.00$

\section{Diversion Program}

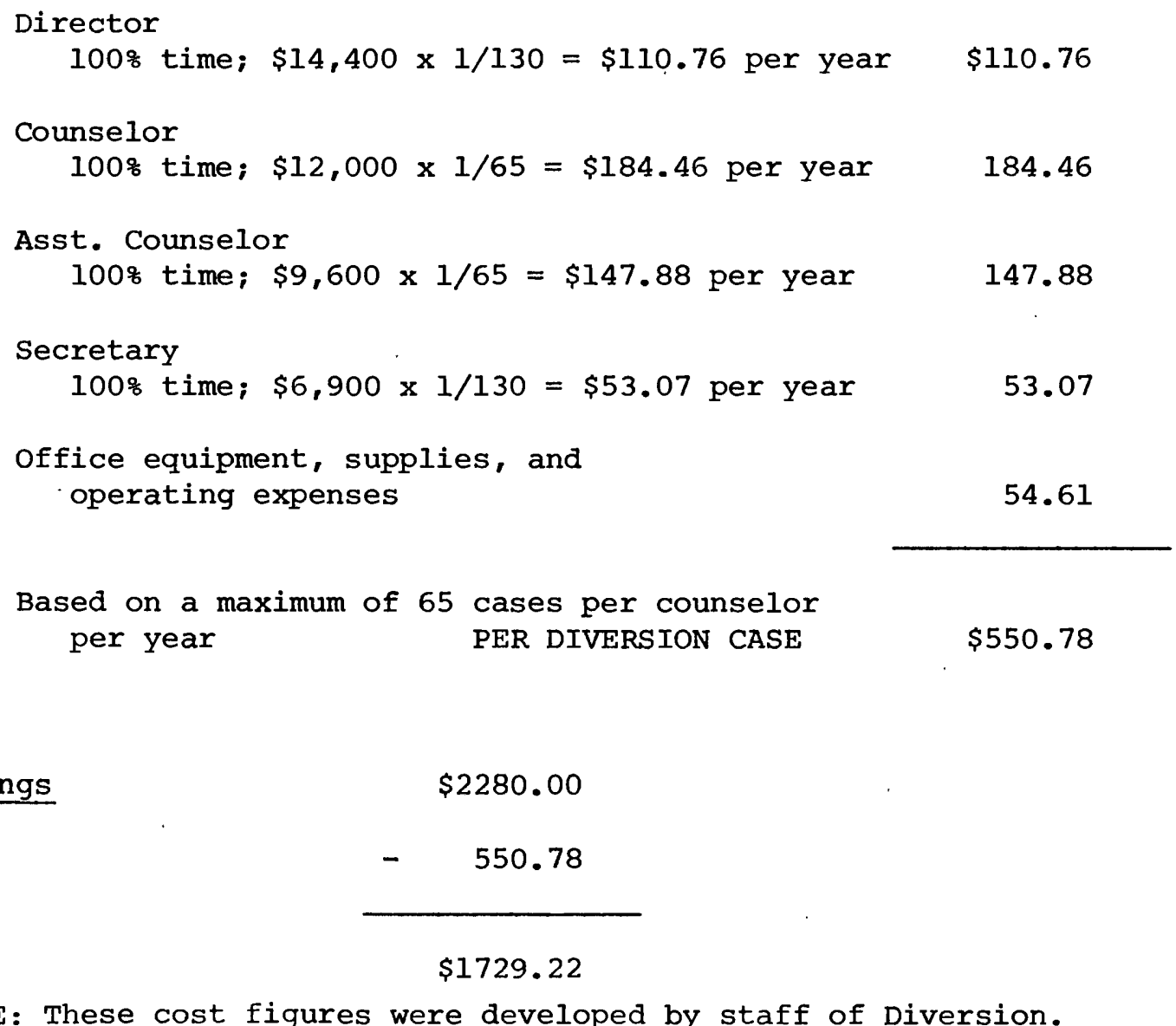

*NOTE: These cost figures were developed by staff of Diversion. 
This cost analysis reflects the work of the Pre-Trial Diversion staff. A count of the questionnaires for 1976 actually revealed $1 / 2 \mathrm{~N}$ to be 74, which means that the $\mathrm{N}$ for 1976 was approximately 150, not 130 . The budget was $\$ 46,475$ per year by 1976 . In 1978 , the budget increased to $\$ 67,029$. Using the 1976 and 1978 budgets, it was possible to extrapolate for 1977 and determinate approximate costs per diversion case.

TABLE 10

\begin{tabular}{|c|c|c|c|c|}
\hline Year & Diversions & Budget & Actual Cost & Savings \\
\hline 1976 & 150 & $\$ 46,475$ & $\$ 630$ & $\$ 1650$ \\
\hline 1977 & 130 & $\$ 56,752$ (approx) & $\$ 670$ (ap) & $\$ 1610$ \\
\hline 1978 & - & $\$ 67,029$ & -- & -- \\
\hline
\end{tabular}

Using the same method of computation for 1976 as in Table 9, recalculated savings would be $\$ 1650$ per person and for $1977, \$ 1610$, and actual cost for 1976 would be closer to $\$ 630$. The court costs are based on the 1976 declaration; however, they do not reflect more recent costs. In addition, Cascade Research Center is currently collecting cost data independent of the Diversion staff to retain objectivity and obtain greater detail in cost analysis breakdowns. It is clear that, according to this method of determining cost efficiency, diverting offenders results in a positive gain or savings over traditional adjudication procedures for clark county. 


\section{Pre-Habilitation Activity}

The extent of supervision over the offender by the assigned PreHabilitation counselor varied from case to case. Basic conditions included obtaining and maintaining a job, living in a stable situation, contacting counselors on a regular basis, and paying program fees. Those required to adhere to the basic conditions plus several more were categorized as receiving high supervision (for data collection purposes only). Medium and low were choices for the remaining persons, with medium covering basic conditions and low, minimal conditions. Over 68 percent received high supervision (141); 21 percent, medium (43); and 6 percent (13), low. Seven cases were missing. Referrals made to other community agencies or resources were varied. First referrals were highest to employment services at 39 (19.0 percent). Mental health counseling was second at 21 (10.2 percent). Much smaller percentages were reported for the following: drug counseling, armed services, alcohol counseling, CETA, housing, vocational rehabilitation, health services, and schooling. over 59 percent did not receive referrals. Second referrals were highest to mental health counseling and drug counseling with scattered low percentages going to health, schooling, employment, vocational rehabilitation, alcohol counseling, armed services, food, and CETA. The amount of third referrals was small, adding up to 5.5 percent of the whole and was similar to the second referral grouping.

Of interest to Pre-Habilitation were the types of program violations committed as rationale to terminate offenders from the program. For 24 cases, 13 (52.0 percent of unsuccessfuls) failed to keep con- 
tact with the agency and counselor as their first violation. Seven or 28 percent violated basic rules of the program; one failed to find employment; one did not pay program fees; and two committed other violations. Second violations occurred for six persons; third, three persons; and fourth, one person. 


\section{CONCLUSIONS AND RECOMMENDATIONS}

The cost efficiency data reveal that the Pre-Habilitation alternative has been more cost efficient than the traditional court procedure over its five years' existence. An average savings from 19761977 has been approximately $\$ 1620$ per diversion compared to conviction and probation for one year.

At this printing, significant tests of difference are few. A positive correlation $(\mathrm{P}<.03)$ between younger offenders and success rates revealed that anyone under 21 had a higher risk of failure than did older persons. This finding may simply mean that screening for the program has been poor for this group. On the other hand, it may mean that the program does not effectively serve juveniles and young adults.

Recidivism rates for first and second rearrests yielded a total of .5 percent felonious crime and 7.3 percent misdemeanant crime. Comparison data listed 3.0 percent and 5.0 percent figures, respective1y, which leads to the conclusion that Snohomish County is less effective than Clark County if one considers the seriousness of the two types of crime as a basis for effectiveness. More precise definitions of during program and post-program crime rates would yield more conclusive evidence.

Labeling theory, a foundation stone of this program was not tested but should be researched in future studies. To have inquired whether or not a post-program offender internalized a notion of deviancy may have been more revealing than recidivism data alone. Certainly, the inference cannot be made from recidivism data that destruc- 
tive labeling effects have not occurred.

The evaluation literature of pre-trial diversion is not laudatory but perhaps because testing is so difficult. First, access to a very mobile constituency (diverted persons) is limiting. Second, the choice of comparison group as in this study only allows a similar program for comparison, not a study of what would have happened if there were no diversion. For example, recidivism data could be obtained from one who has been prosecuted and sentenced to probation at the same time a like person is not prosecuted and placed on short-term diversion. A matched cohort group would have enhanced and made more valuable this evaluation in order for valid generalizations to be possible across programs on a national basis. Third, to follow large groups of offenders is difficult on account of confidentiality rights.

An evaluation of cost-benefit or the effectiveness of pre-trial diversion must encompass more than the economic and humanitarian components. It is generally accepted that diversion is a significantly less expensive method of dealing with first offenders of less serious felonies and misdemeanors and that by providing little penetration into the criminal justice system, diversion is able to interfere with the process of labeling. However, the effectiveness issues ask more questions such as Lundman's desire for adequate study of the effects of past practices for comparison as well as an analysis of the difference between diversion and probation services and Agopian's demand for clear definition of treatment criterion, specific evaluation goals, and attention to the the complexities of gathering appropriate data. In addition, investigation is necessary into the potential 
concern over increasing the discretionary powers of criminal justice officers and prosecuting attorneys. Certainly fitting into an evaluation of effectiveness is a review of controversial evidence that the severity of punishment may deter criminal deviance as well as avoidance of starting the labeling process.

While the literature is replete with poor examples of and problems in diversion evaluation, clearly this research provides initial findings which promise rich results in the forthcoming completion of the clark county program evaluation. Incoming results of the telephone survey, innumerable crosstabulations, and more detailed and independent cost analysis figures will contribute to national as well as local evaluation needs since pre-trial diversion, in its decade of existence, has not provided valid data on efficiency and effectiveness. Further, the creation of crosstabulations will meet the social scientist's needs for demographic descriptions. To challenge the researcher, cost-effectiveness remains an unsolved question. Its answer may determine the future of diversion practices. 
Aaronson, David E.; Nicholas N. Kittrie; and David J. Saari. Alternatives to Conventional Criminal Adjudication: Guidebook for Planners and Practitioners for the National Institute of Law Enforcement and Criminal Justice, Washington,D.C.: U.S. Government Printing office, November, 1977.

Agopian, Michael $w$. "Politics of Evaluating Diversion Programs," Evaluation Quarterly, 3(1):81-88, February, 1979.

Alper, Benedict S. Prisons Inside-Out: Alternatives in Correctional Reform, Cambridge., Massachusetts: Ballinger Publishing Co., 1974.

Beha, James; Kenneth Carlson; and Robert H. Rosenblum. Sentencing to Community Service for the National Institute of Law Enforcement and Criminal Justice, Washington, D.C.: U.S. Government Printing Office, 1976.

Blomberg, Thomas. "Diversion and Accelerated Social Control," Journal of Criminal Law and Criminology, 68(2):274-282, June, 1977.

Blumberg, Richard. "Prison Construction Policy and Alternatives," research report, unpublished, Washington, 1978.

Bohnstedt, Marvin. "Answers to Three Questions about Juvenile Diversion," Journal of Research in Crime and Delinquency, 15 (1):109-123, January, 1978 .

Duffee, David and Robert Fitch. An Introduction to Corrections: A Policy and Systems Approach, California: Goodyear Publishing Co., Inc., 1976.

Galaway, Burt. "The Use of Restitution," Crime and Delinquency, 23 (1): 57-67, January, 1977.

Gilbert, G. Ronald. "Alternate Routes: A Diversion Project in the Juvenile Justice System," Evaluation Quarterly, I(2):301-318, May, 1977.

Gottheil, Diane I. "Pretrial Diversion: A Response to the Critics," Crime and Delinquency, 25 (1):65-75, January, 1979.

Harris, Carl M. and Soumyo D. Moitra. "Improved Statistical Techniques for the Measurement of Recidivism," Journal of Research in Crime and Delinquency, $15(2): 194-213, \mathrm{July}, 1978$.

Lundman, Richard J. "Will Diversion Reduce Recidivism?" Crime and Delinquency, $22(4): 428-437$, October, 1976. 
Mullen, Joan. The Dilemma of Diversion: Resource Materials on Adult Pre-Trial Intervention Programs for the National Institute of Law Enforcement and Criminal Justice, Washington,D.C.: U.S. Government Printing office, 1974.

Nimmer, Raymond T. Diversion: The Search for Alternative Forms of Prosecution, Chicago: American Bar Foundation, 1974.

Noble, John H., Jr. "The Limits of Cost-Benefit Analysis as a Guide to Priority-Setting in Rehabilitation," Evaluation Quarterly, 1(3): 347-377, August, 1977.

Perlstein, Gary R. and Thomas R. Phelps, eds. Alternatives to Prison: Community-Based Corrections, California: Goodyear Publishing Co., Inc., 1975.

Prosecutor's Diversion Program, Vancouver, Washington: Clark County Prosecuting Attorney's office, 1978.

Quay, Herbert C. and Craig T. Love. "The Effect of a Juvenile Diversion Program on Rearrests," Criminal Justice and Behayior, $4(4)$ : 377-396, December, 1977.

Roesch, Ronald. "Does Adult Diversion Work: The Failure of Research in Criminal Justice," Crime and Delinquency, $24(1): 72-80$, January, 1978.

Interview with Harley Lieber, Alternative Community Services, Probation Services, Multnomah County, Portland, Oregon, February, 1979. 
APPENDIX

APPENDIX A: Admission Criteria to the Pre-Trial Diversion Program, Clark County, Washington.

APPENDIX B: Computer Worksheet which was originally developed from the questionnaire; abbreviated items reflect those questions. Computer formating was added to create the worksheet. 
APPENDIX A

ADMISSION CRITERIA

(Clark County Adult Diversion Program)

First order of Inquiry

Age of offender - no requirement.

Previous record - the present offense shall not constitute part of a continuing pattern of anti-social behavior.

Nature of the offense -- the offense shall not be of ar assaultive or violent nature, whether in the act itself or in the possible injurious consequences of the act. This may be interpreted to permit consideration of some selected offenders including indecent exposure, indecent liberties, and similax sex crimes.

Admittance of guilt - the offender must accept moral responsibility for whatever his behavior in the alleged offense.

Restitution to the victim -- consideration should be given for full restitution to the victim with the details of such to be worked out by Pre-Hab.

Residency - the offender should live within an area which makes close supervision feasible, with special arrangements for college students.

- Controlled substances - offenders involved in controlled substance offenses will meet the following criteria:

(a) the amount is small;

(b) the material is intended for the use of the person arrested;

(c) the person does not have a history of participation in the drug scene.

Excluded from consideration for diversion are drug offenses involving large amounts and offenses involving delivery/selling.

Second oxder of Inquiry (are benefits outweighed by prosecution costs?) The extent of harm caused by the offense;

Possible improper motives of a complainant;

Reluctance of the vicim to testify;

Effect of nonenforcement upon the community sense of security and confidence in the criminal justice system;

The direct cost of prosecution in terms of prosecutorial time, court time, and similar factors;

Prolonged nonenforcement of the statute on which the charge is based; Availability and likelihocd of prosecution and conviction by another jurisdiction:

Any assistance of the accused in the apprehension and conviction of other offenders, in the prevention of offenses by others, in the reduction of the impact of offenses committed by himself or others upon victims, and in engaging in any other socially benefiting activity that might be encouraged by not prosecuting the offender; and The effect of nonenforcement on the police department morale. 


\section{APPENDIX B}

COMPUTER WORKSHEETS

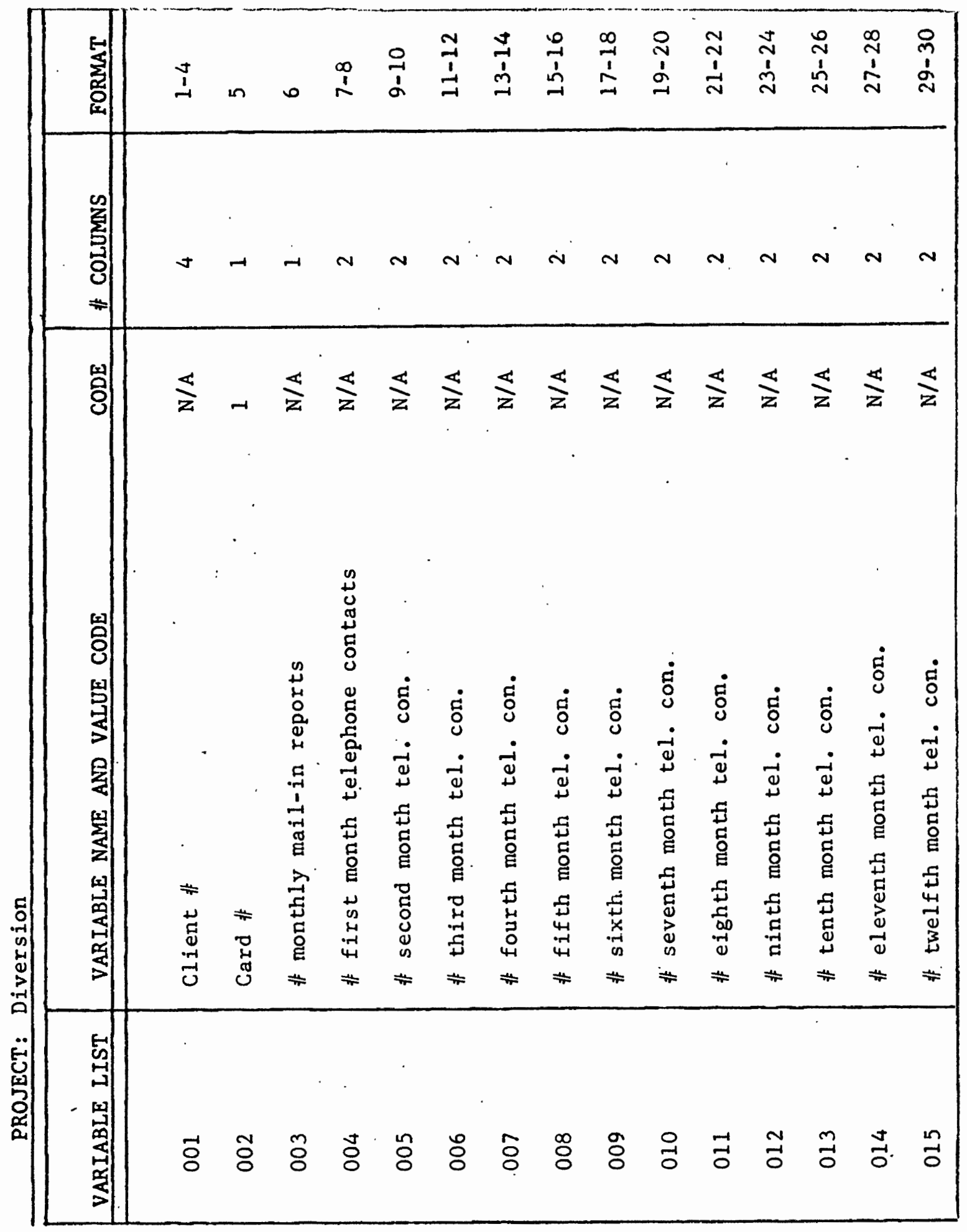




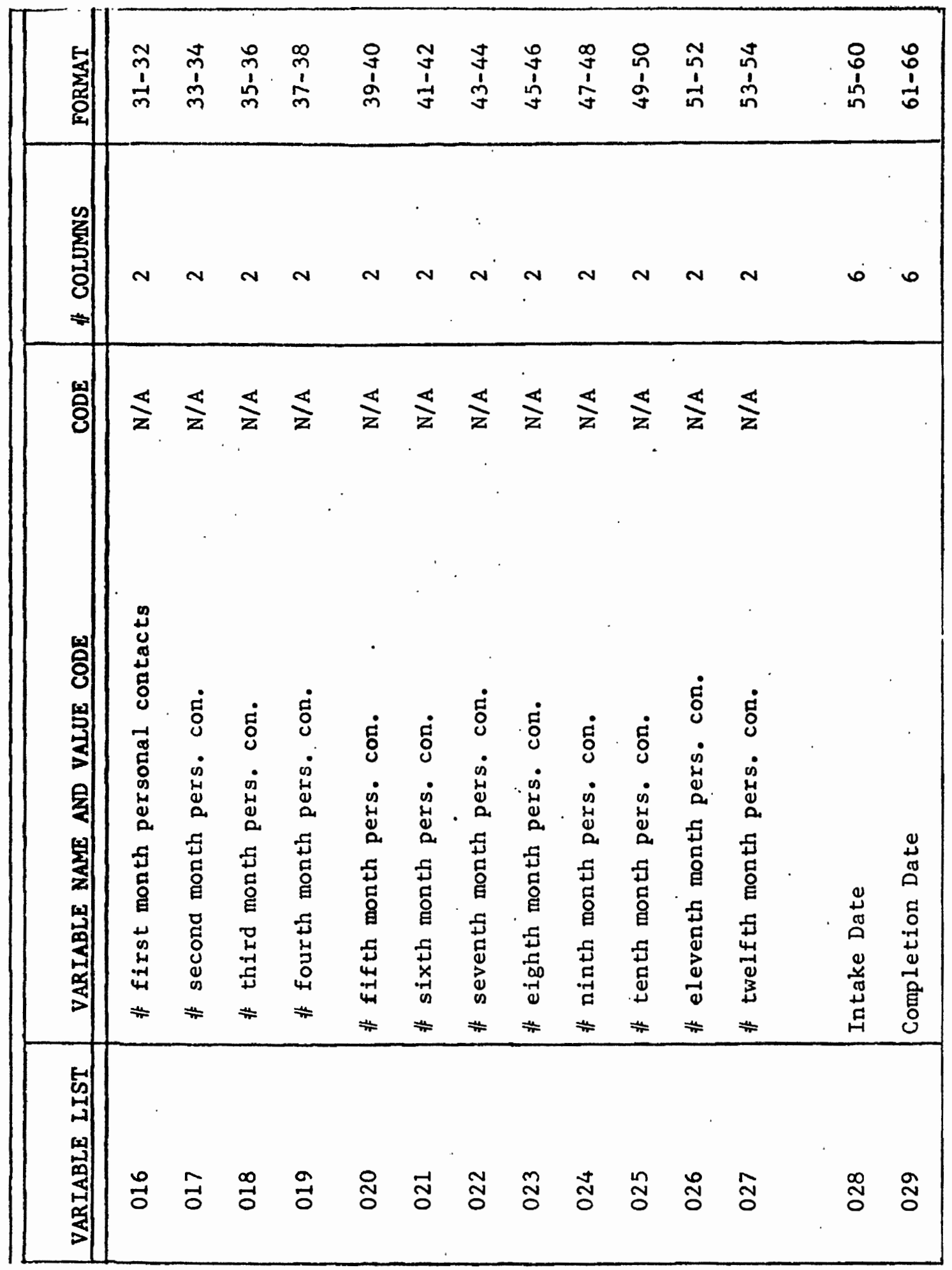




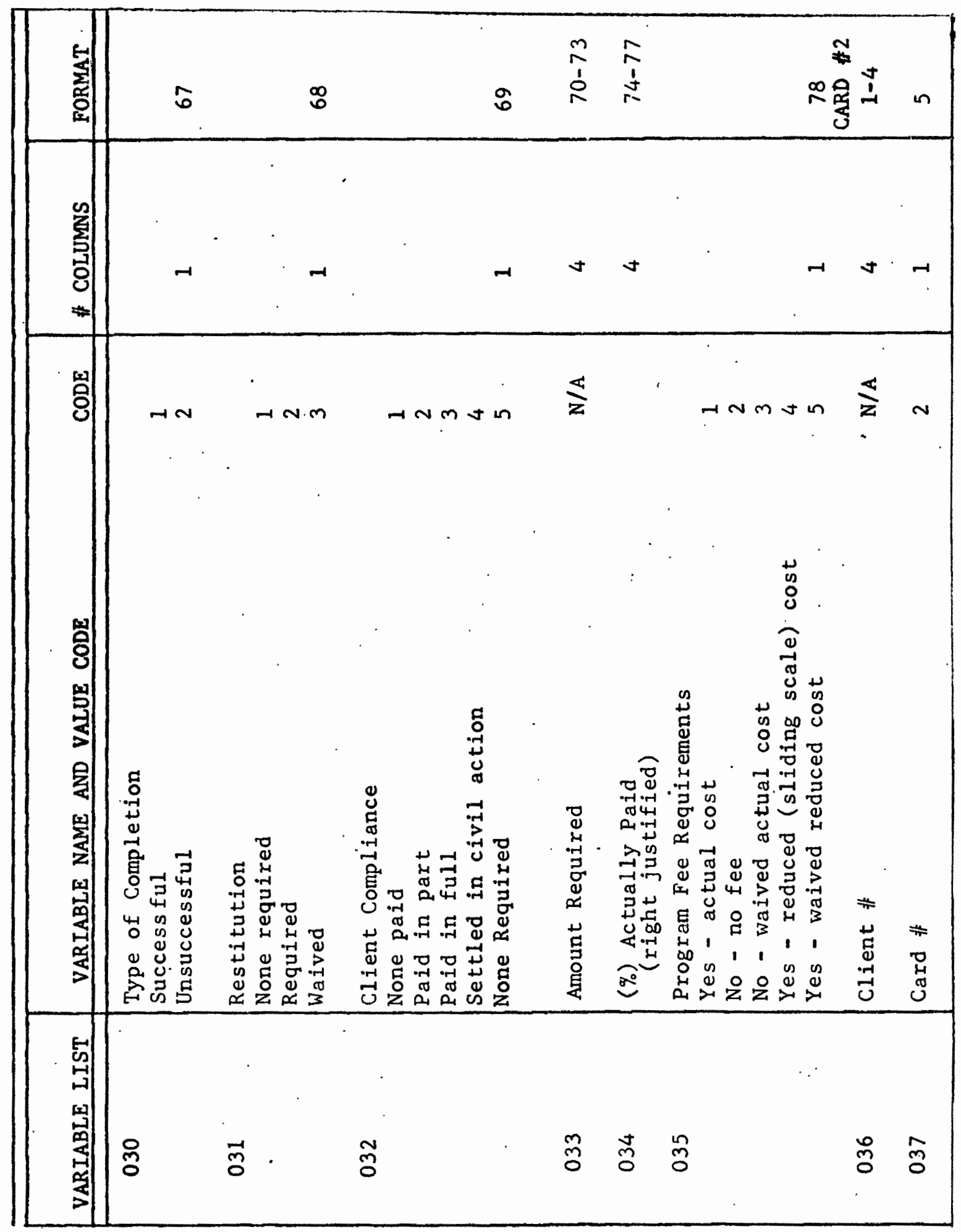




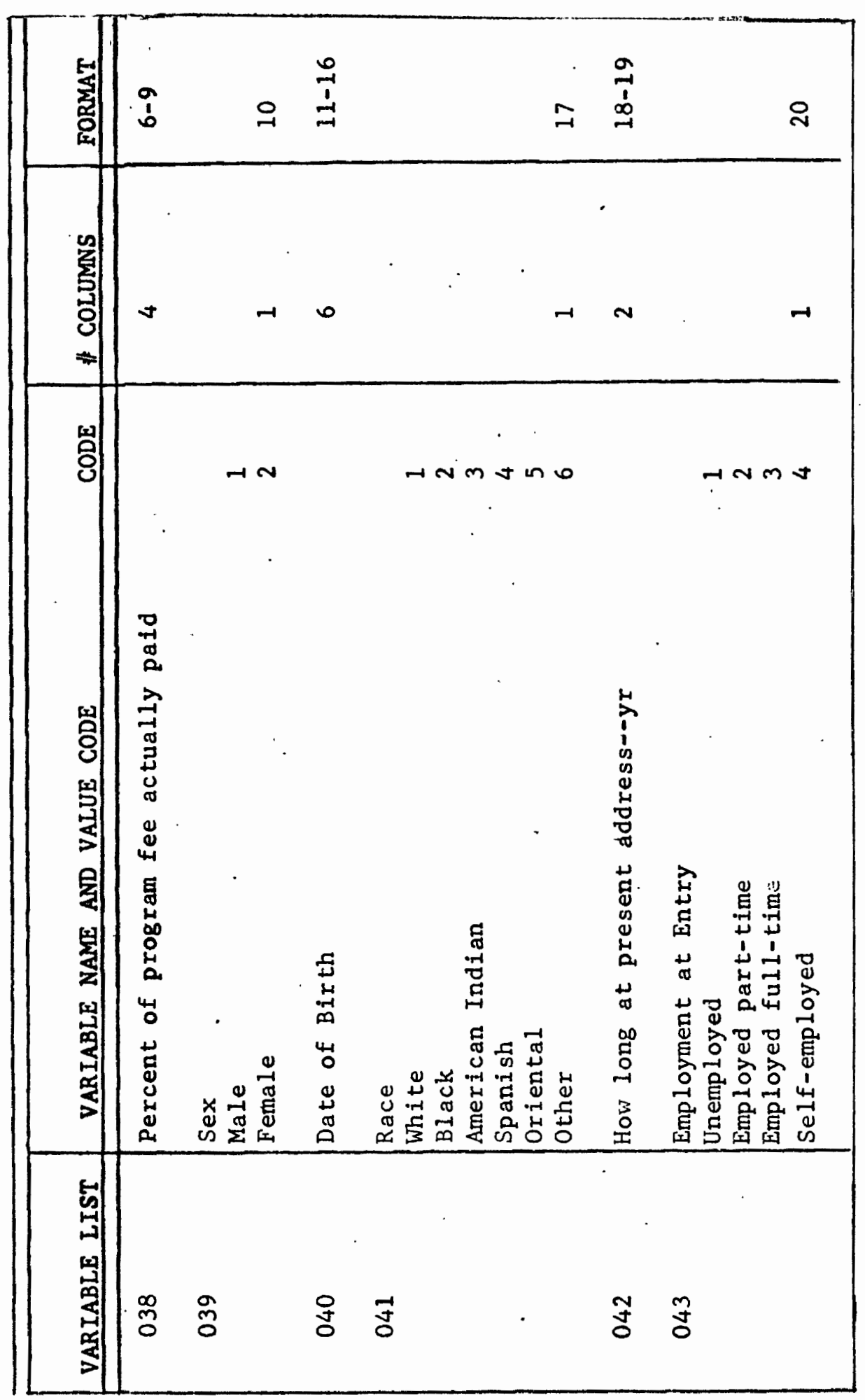




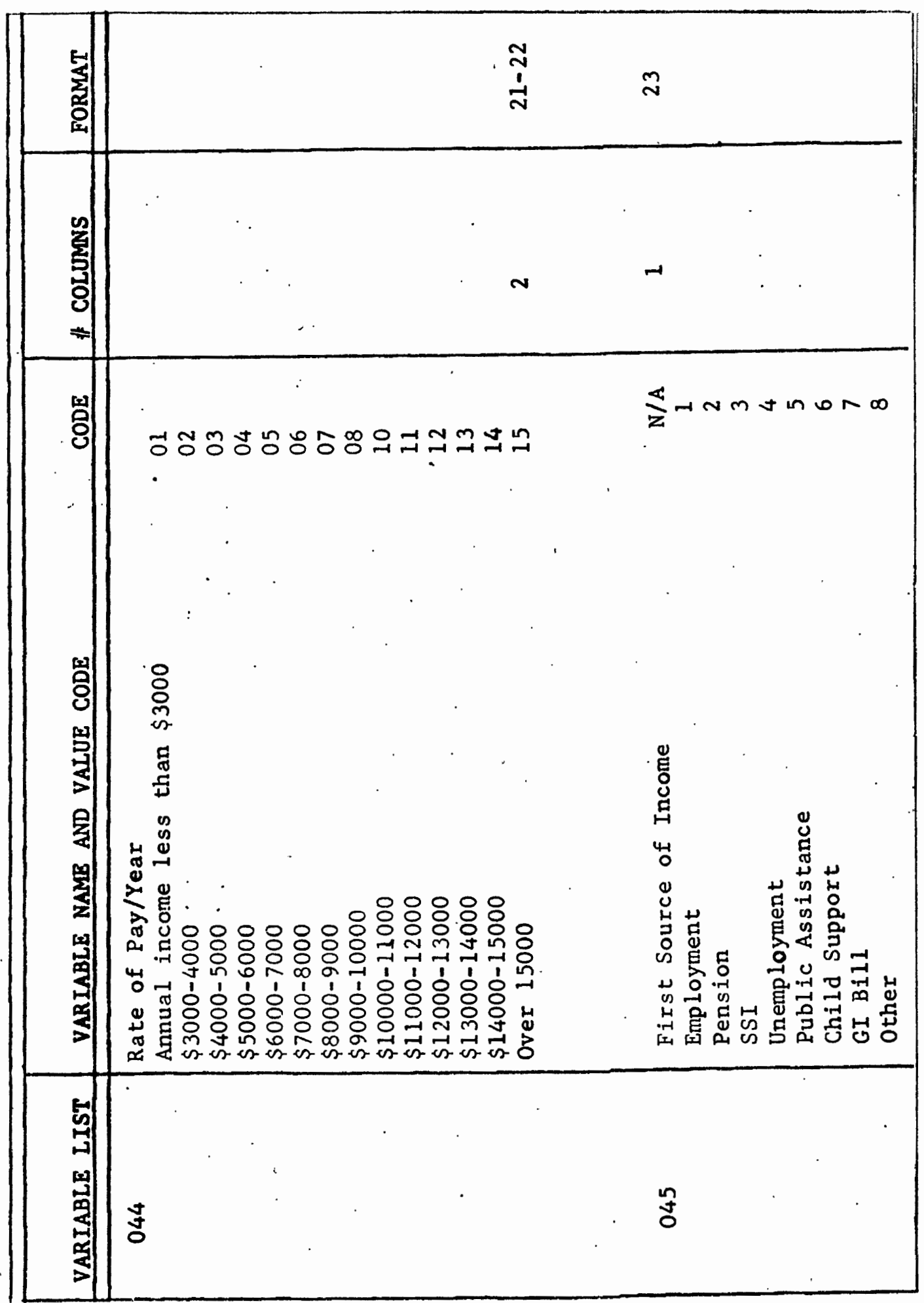




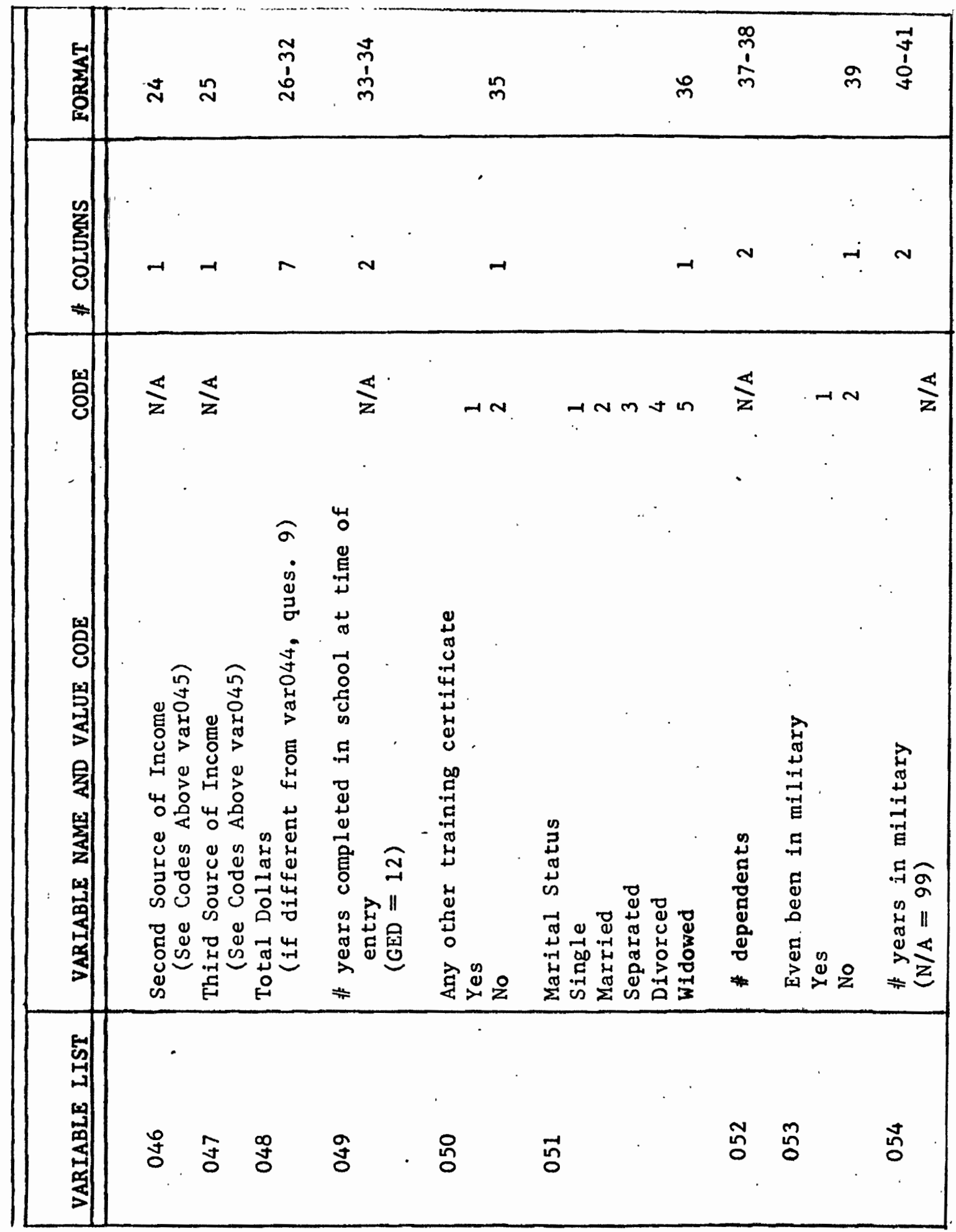




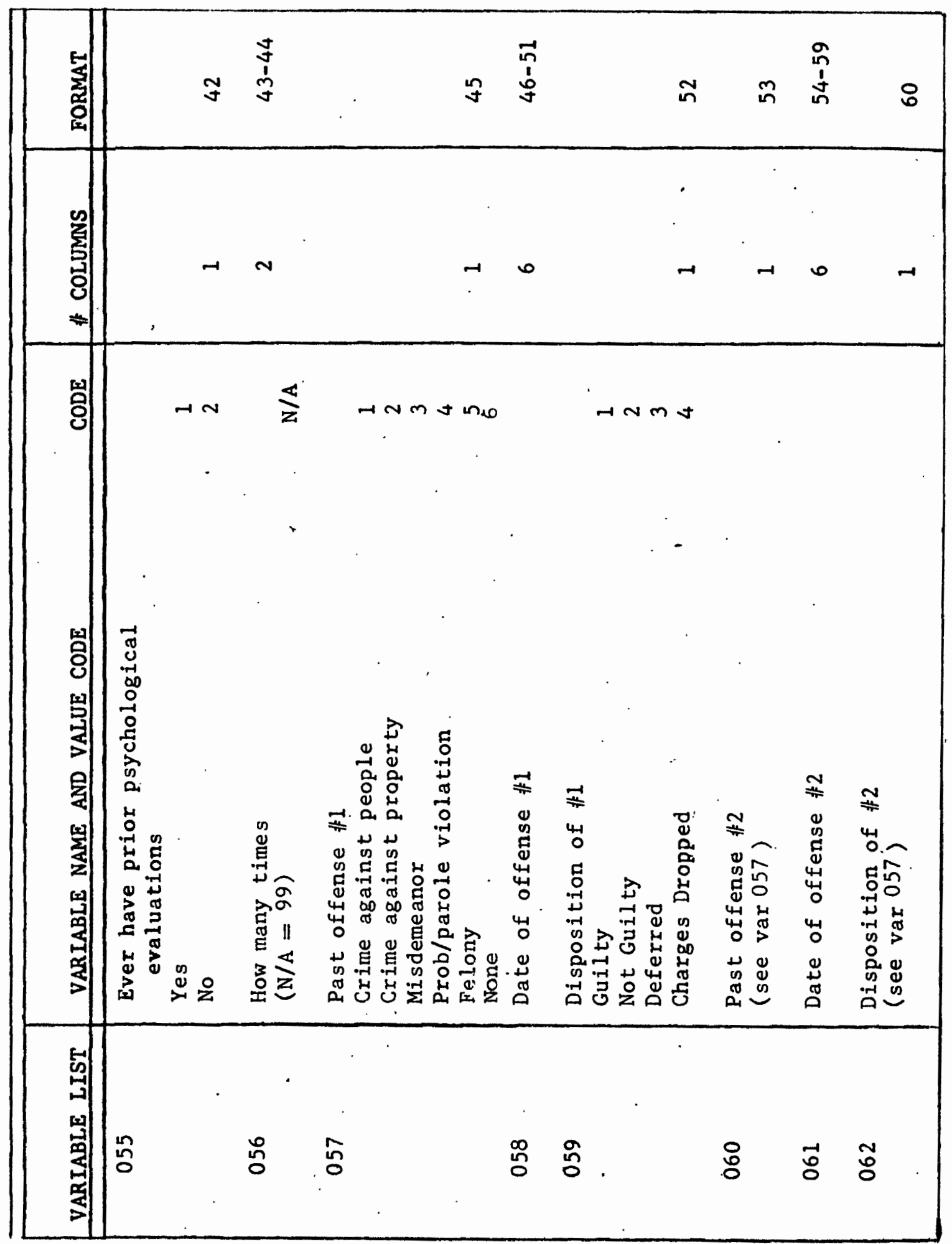




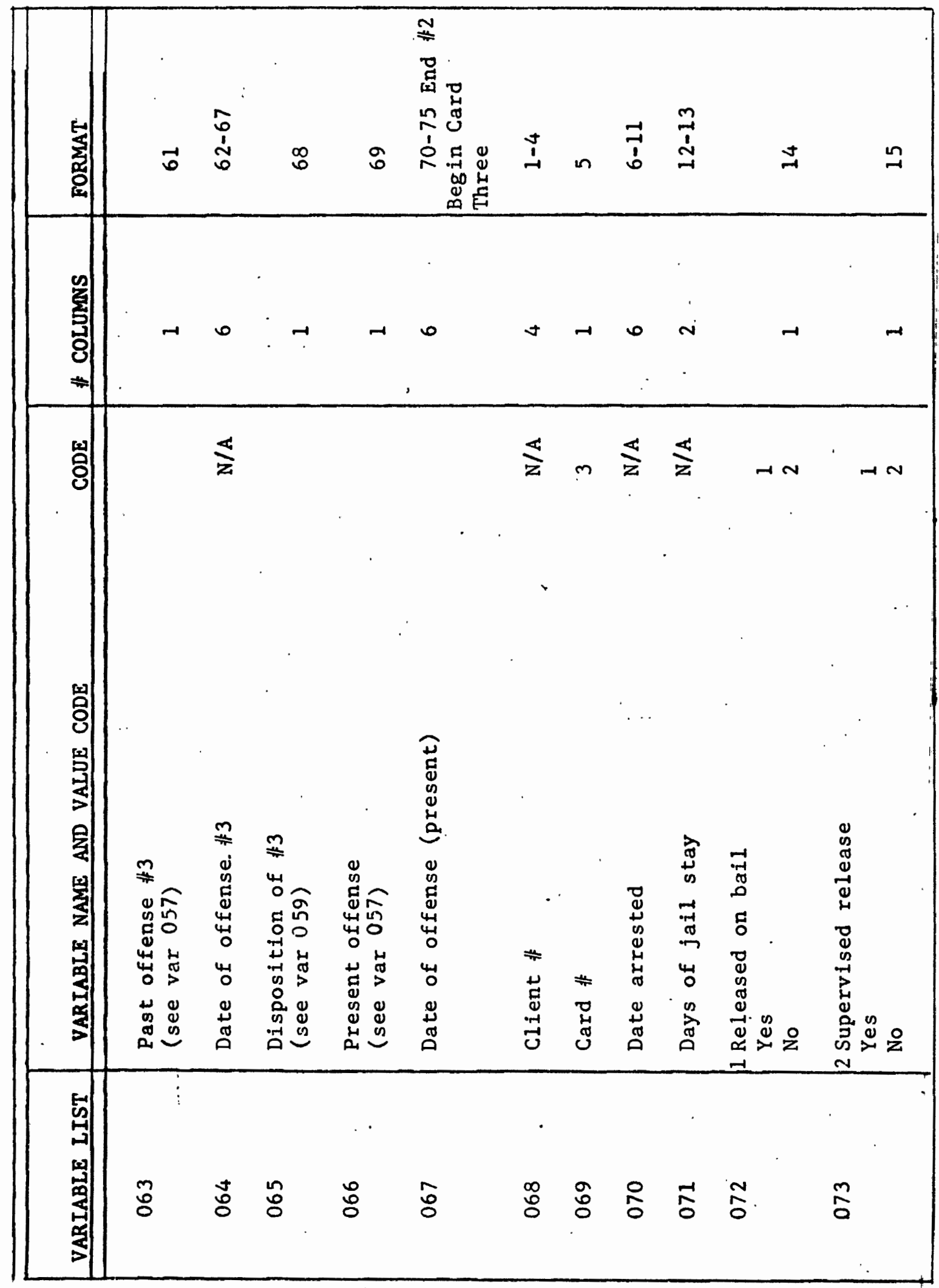




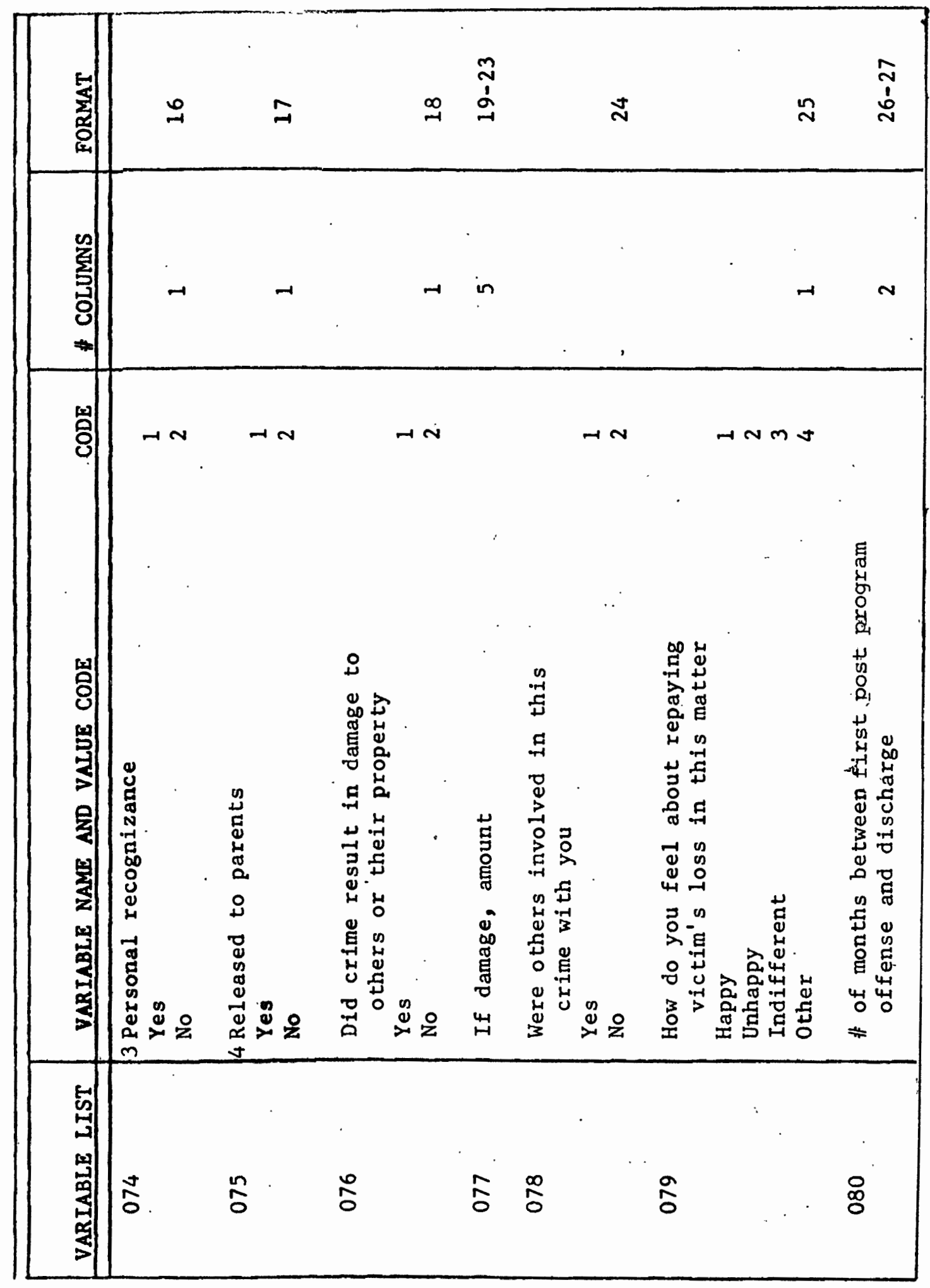




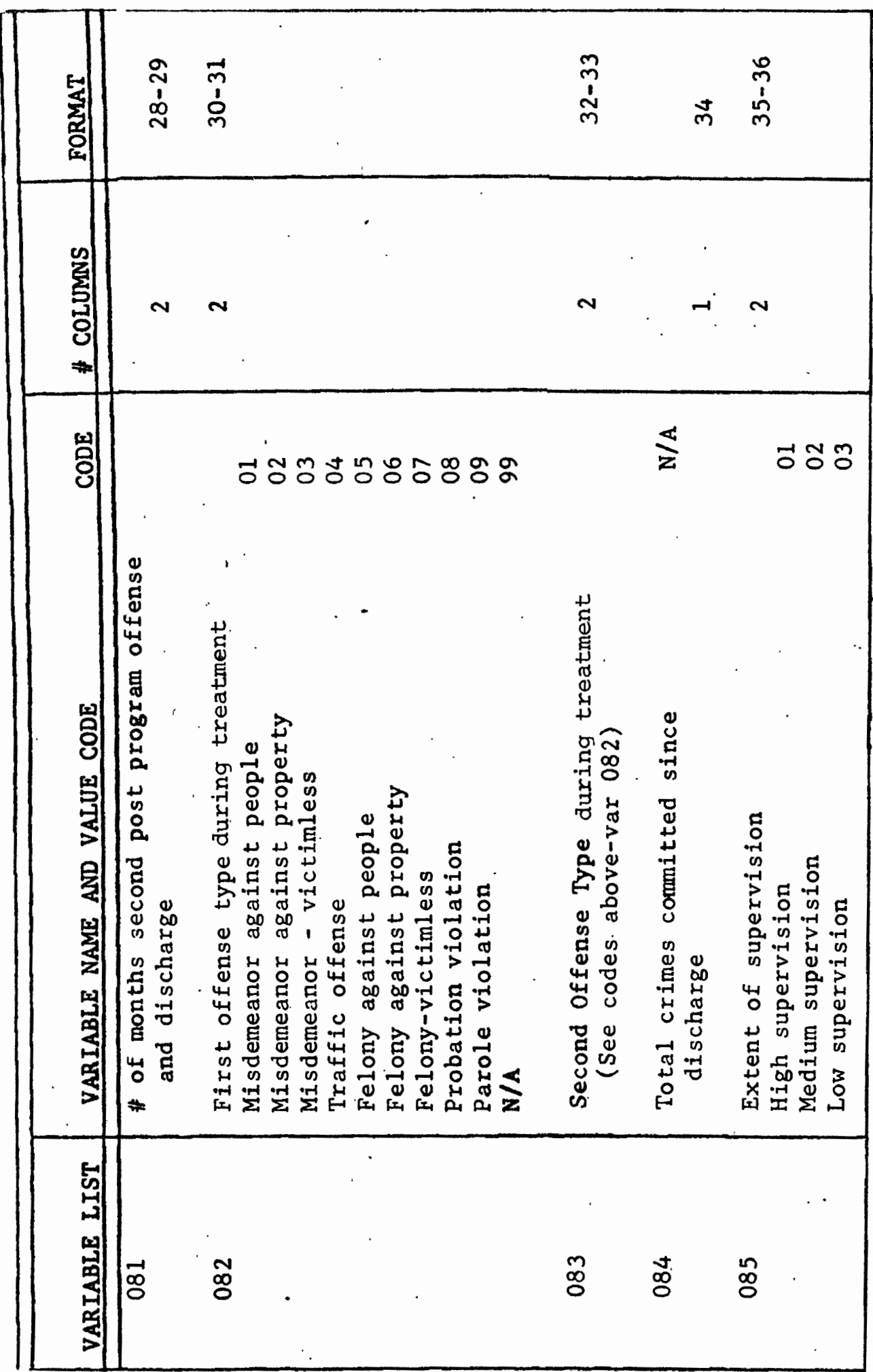




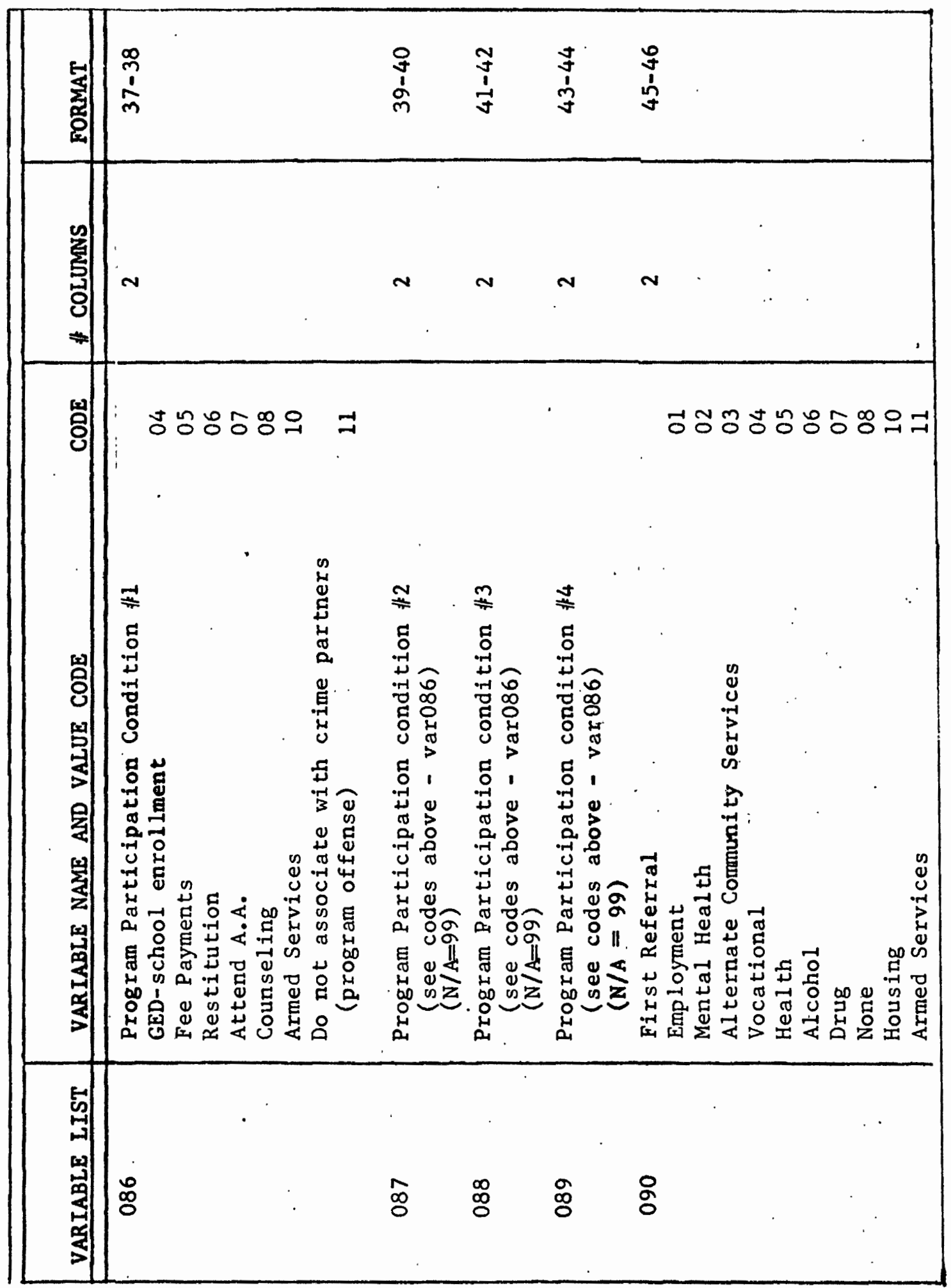




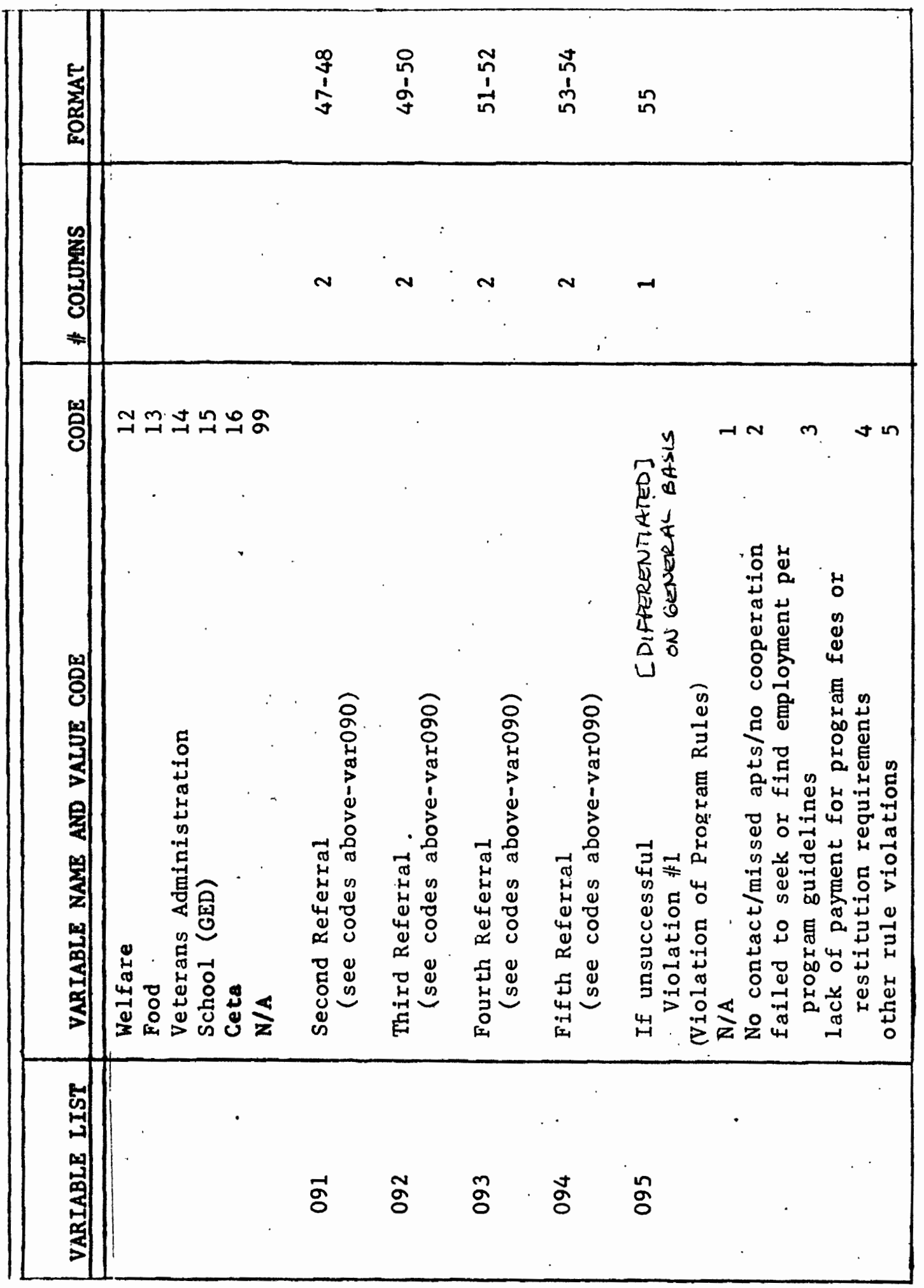




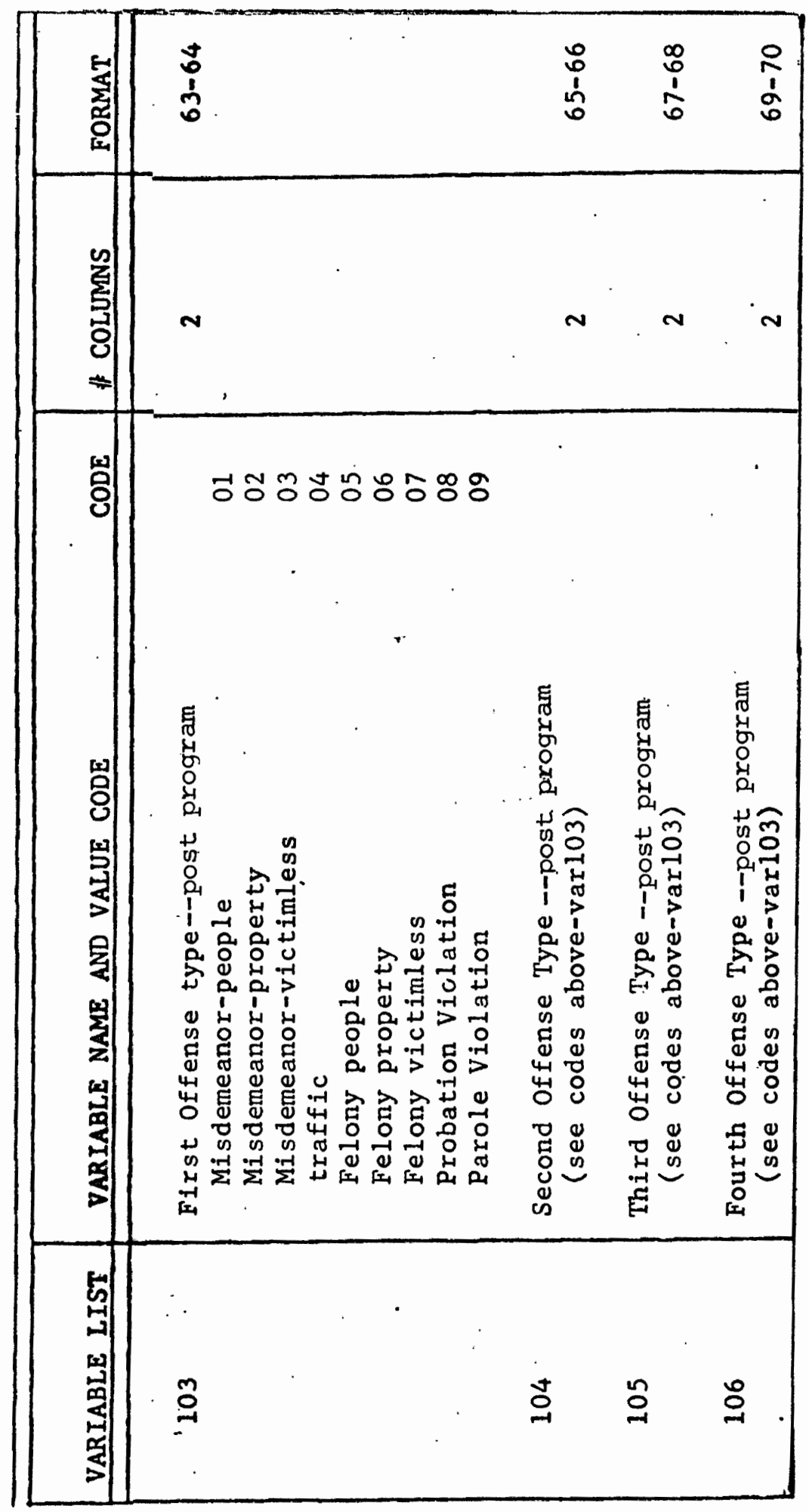




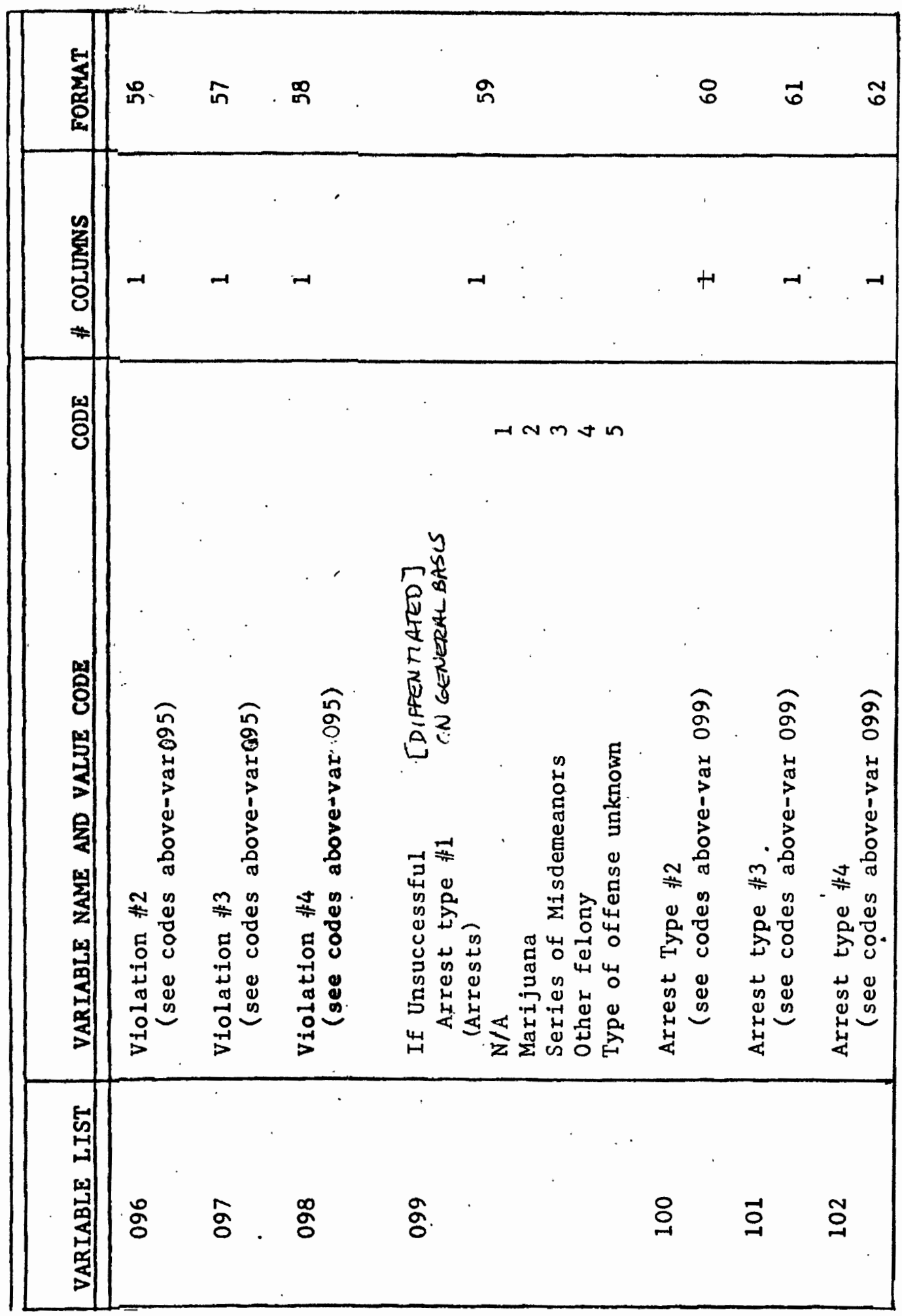

